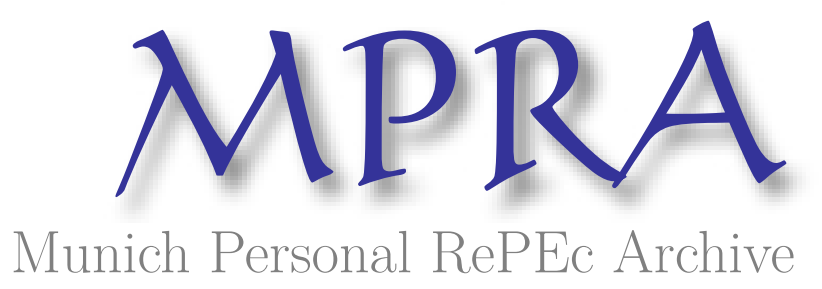

External determinants of small business survival - The overwhelming impact of GDP and other environmental factors and a new proposed framework

GUIMARÃES BARBOSA, EVALDO

15 August 2016

Online at https://mpra.ub.uni-muenchen.de/73346/

MPRA Paper No. 73346, posted 28 Aug 2016 12:19 UTC 


\title{
EXTERNAL DETERMINANTS OF SMALL BUSINESS SURVIVAL - THE OVERWHELMING IMPACT OF GDP AND OTHER ENVIRONMENTAL FACTORS AND A NEW PROPOSED FRAMEWORK
}

\author{
Evaldo Guimarães Barbosa*
}

\author{
August 2016 \\ (Very preliminary version!)
}

\begin{abstract}
This article claims that the basic relationships between, on the one side, the small firms' hazard of exit, and, on the other side, the GDP growth rate and the industry growth rate are Ushaped. This means that there are more births and deaths for this segment of manufacturing enterprises during both cyclical downturns and booms in the economy. Higher competition in the economy in the first case comes from necessity entrepreneurs and in the second case from opportunity ones. The article also claims that the quadratic specification would rarely be the most adequate, since other combinations of different pairs of exponents would certainly better capture nuances of the relationships being regressed, in view of the fact that the actual Ushaped relationship is rarely symmetric. This is exactly why the artificial exclusive monotonic fitting normally produces parameter estimates that signalize the existence of a decreasing relationship. So, what may wonder many people, the invariably detected inverse relationship is not caused by the second half segment (where the economic upturns occur) of the continuous of the GDP growth rate, but rather by the first (where the economic downturns occur), whose impact on the hazard of exit is normally stronger. Also, even a direct relationship may occur because of this asymmetry and findings of lack of statistical significance result from a misguided attempt to fit a linear specification to a perfect, or almost perfect, symmetrical actual U-shaped relationship. The article conclusively claims that these realizations, and the fact that authors overfit by specifying contemporaneously the GDP growth rate, the industry growth rate and the industry entry rate, explain findings in the extant literature that are awkward, unexpected and embarrassing and interpretations that are many times completely inapplicable.
\end{abstract}

\section{"Common sense is the collection of prejudices acquired by age eighteen" Albert Einstein.}

\section{INTRODUCTION}

First of all, a word has to be said about the work schedule set out in Barbosa (2016b)'s previous working paper. At that moment, inspired by Low and MacMillan (1988)'s thinking, it was said there was the intention to carry out a revisionary work of the small business survival empirical investigations, but that, as the field was very vast, the task would be tackled step by

*BARBOSA is a retired Tax Officer at the Federal Tax Secretariat in Belo Horizonte City, Brazil. He was formerly an Assistant Professor of Finance at the Federal University of Viçosa. He worked also for enterprises, such as Petróleo Brasileiro S/A. He used to be a Consultant to SMEs in the former governmental Brazilian Center to Support Small and Medium Enterprises. Today, he is an independent researcher, writer and consultant in the small business field.

E-mail: evaldogb@yahoo.com.br 
step, initiating with only size, age and growth. As it is natural to think that from that start the sequence would proceed to deal with other factors playing a role at the level of the enterprises, and then, others at the level of industry, and last of all, the ones at the level of the economy, it might come surprisingly that the second theme, to be tackled in this second paper, is GDP growth. The answer to this is that the other factors were dealt with to some extent in Barbosa (2009). On the other hand, the GDP growth rate and other external factors have been less explored and have implications too much influential to delay reporting, if the Low and MacMillan (1988)'s main preoccupation, namely, to derive the maximum benefit from future research, deserves due consideration.

Geroski and Others (2010) present a summary review of works dealing with factors at the level of the macro environment of the firm and others at the level of the firms' industry. A question about these studies concerns the generalizability of their conclusions, since it remains to be demonstrated whether they worked with genuinely new small enterprises. For example, Bertin and Others (1996), the first quotation by Geroski and Others (2010) in their the macroeconomic environment subsection, dealt with the blast furnaces business, which is by no means a manufacturing sector where small firms are prevalent. Then, there is Boeri and Bellmann (1995), another work quoted by Geroski and Others (2010), who, by way of informing that there is little, if any, under-sampling of small and young establishments in their study, state that this is important because the neglect of very small establishments prevents the observation of an important component of the selection process following the entry of plants in an industry. However, these very same authors report results individually for many manufacturing sectors, but not for the ones where the small firms are prevalent the most.

In the case of some of these studies, weaknesses in their generalizability may be told from their results too. For example, the understanding associated to Caballero and Hammour (1994)'s work that, by reducing the rate of new firms creation, recessions alleviate the pressure exerted upon established units, may only possibly come out from a sample of large enterprises in developed countries. It is in times of recessions that people hear of many unemployed individuals starting formal and informal new businesses. Consistent with this, Fotopoulos (2014) reported in a graph a pattern over time of net entry consistent with Caballero and Hammour (1994)'s results only for the larger enterprises in his Greek sample of manufacturing enterprises. For the smaller enterprises results are surprisingly quite different.

Some authors describe their sample composition and/or strategy and this helps to understand strange results. This is the case of Carreira and Teixeira (2011), who declared that their sample included all enterprises with more than a hundred employees, considered only a sample of the ones with more than twenty but less than a hundred employees and did not select any with less than 20 employees. This is a strange sample composition and results from it were consistently with the sampling strategy different from those of the majority of the other authors.

The other way round of the under-representation of the small firms is the mixing together of all sizes of enterprises. This is the commonest happening in the empirical literature. In this case, as the small firms are much more numerous than the medium- and large-sized ones, results, that should be restricted to them, by breaking down the analyses by size bands, end up being generalized to all enterprises alike. Oh and Others (2009) show that this mistaken generalization can occur, since they present the results discriminated by size ranges and for the entire sample. There is not much difference between the parameter estimates of the small firms' subsample and those of the whole sample. In view of these realizations and the scope of this work, only studies dealing exclusively with large, quoted corporations will not be reviewed in this article. 
Thus, this study is restricted to small firms not only because these enterprises have been receiving particular attention by virtue of their differential nature and social and economic importance, but also because large enterprises' survival probabilities do not seem to depend so much on variations on the GDP growth rate, industry growth rate and recessions. There are some works that confirm this. Oh and Others (2009) reported finding that both sectorial and GDP growth had an impact on the hazard rate only in the classes of the SSEs, with 50 employees or less, and of the MSEs, with more than 50 and less than 300 employees. For the class of the LSEs, with more than 300 employees, these variables were not statistically significant. Mata and Others (1995) reported a table of Cox regressions in which the industry growth rate and the industry entry rate, both time varying, impacted only the hazard of exit of small firms, that is, independent new establishments, than their larger counterparts, multi-establishment enterprises. Holmes and Others (2010) reported finding the initial sectorial growth rate and the initial unemployment rate associated with the survival probability in their subset of microenterprises but not in the SMEs subset, which includes enterprises with up to 500 employees. Calá (2015) reported a table of Poisson model panel analyses for the determinants of firm exits in Argentina, in which the level of informality in the economy, taking here as a proxy for GDP growth, is associated with the exit rate of enterprises only in the group of low-tech industries, which are the traditional manufacturing sectors where the small enterprises are prevalent.

Thus, after qualifying results from previous empirical studies, not much is left in terms of detailed knowledge on the impact of the state of the economy on the small manufacturing enterprises' failure likelihood. One thing has been taken as fact by people overall. This is that the overall state of the economy has long been well known as an important force driving firms either out of business or into business, depending whether times are of recession or boom. When times are tough, established firms face difficulties and the competitive pressure from other incumbent enterprises combined with lower demand may lead them to exit. On the other hand, when times are of boom, the idea is that there is room for everybody, that all enterprises can live in harmony together, and that none has to leave the market and can live longer. These ideas apply also to the specific conditions in the industry where the enterprise operates.

When the econometric findings differ from this, explanations are found as if they were dictated by common sense. Audretsch and Others (2004), for example, concluded that the impacts of the industry R\&D and the industry growth rate on the likelihood of survival were negative and that such a finding supported the hypothesis that survival is more difficult for firms entering an industry in the earlier stages of the life cycle where the knowledge conditions tend to be characterized by high uncertainty, asymmetries and high transactions costs. However, the industry R\&D is totally statistically insignificant in all five studied time spans and the industry growth rate in the two longest ones. In fact, it is clear from the reverse time sequence of both the industry growth rate and the industry entry rate that the explanation is an econometric issue. Shiferaw (2009)'s words with respect to the findings of reversed signs from expected ones were that the unexpected behavior of the industry growth rate suggested that markets are strongly competitive and less efficient establishments do not survive longer even during periods of industry expansion and, concerning the unexpected behavior of the industry entry rate, that entrants do not pose a significant threat to incumbents and so entry is generally a poor substitute for active competition among incumbents in a given market. Again, the real explanation lies in the fact that the two variables are non-linearly correlated. Harris and Li (2010)'s position concerning their unexpected result was that rather than provide a cushion to firms, output growth at the industry level increases the hazard rate of closure, but at a much higher rate for the oldest firms, who are more vulnerable to an expansion of the market. In this case, the explanation has to do with underfitting of the model. 
The above common sense explanations might be seen as disparaging the studies that gave rise to them. This is not the view here. They are normal steps in the evolution of any science. Probably any scholar would be tempted to resort to such dictates of the common sense in carrying out investigations while the research field were yet in its infancy. It is to their accumulation and to the fact that in some cases they contradict each other that is due the realization of the U-shaped relationship that is the main insight of this work.

There is exception, though. Farinha (2005)'s words concerning the finding of an unexpected positive sign of the GDP growth rate were that, at first sight, the result is surprising, but it may be due to the effect of stronger competitive pressure during booms which could also intensify exit. She is right! It is a pity that apparently this perception has not driven her to try to fit a quadratic specification for the GDP growth rate.

It is puzzling that some authors formally acknowledge both the existence of two different views about the influence of the general economic climate on entry, namely the "pull" hypothesis and the "push" hypothesis, and the existence of a high positive correlation between entry and exit (Ilmakunnas and Topi 1999; Andraz and Others 2015), and, even so, no one has ever tried to specify the GDP growth rate and the industry growth rate quadratically, the dependent variable being either the entry rate or the exit rate.

By using data and insights from a study that investigated the common determinants of the firm's capital structure and of business survival, it is possible to investigate in-depth the relationships between, on the one side, the small manufacturing enterprises' hazard of exit and, on the other side, the GDP growth rate and the industry growth rate. This particular research work is uniquely suitable to such an end in view of the facts that it has dealt with a complete array of variables measured at the firm's operations level, besides including in the analyzes both industry and economy level covariates, made use of many non-linear specifications, and achieved a very high degree of explanation of the total variation in survival probability.

However, for many reasons, this reference study does not claim to have the robustness necessary to back strongly its main theses. A major reason concerns its small sample size. To overcome this weakness, the extant literature will be used whatever the way it is possible to bring about evidence in support of these theses. As empirical studies on the impact of the macroeconomic environment upon the small firms' survival prospects have been accumulating for a long time now, a considerable amount of insights, contradictions and flaws are available for reviewing. This is the second major source from where support for the main theses of this study will be eagerly sought. With the insights made possible by the analysis in the reference study, the unexpected, "contradictory" and "awkward" results reported in the literature on the external determinants of business survival can be clarified, the better the more relevant additional information is provided by the research reports. It is understood that the better the reference study clarify these "strange" results the stronger the empirical support lent by the corresponding works to the reference study theses. A third source, though minor in view of the fact it is not sizeable, consists in results from studies in related fields that indirectly lend support to the findings of the reference study.

The achievements of the present study are surprisingly numberless and diversified. First statistical significance is generally very high. The GDP growth rate and the industry growth rate are confirmed as major determinants of the small manufacturing enterprises' hazard of exit. This is robust in specifications that these factors enter either by themselves or together with other sectorial and macroeconomic variables. Only that the relationships are U-shaped. When fitted contemporaneously with the variables investigated in the original, reference study, The GDP growth rate behaves in a way consistent with the interpretation that the state of the macroeconomic 
environment strongly determines that small enterprises will exit, but what determines which ones will exit is the strategies set at the level of the small enterprises and the risks they individually face. Also, consistent with the common sense, the enterprises that have more debt, that are facing higher risks, and, against theory, that should be shielded because are operating in niche markets, are the most affected by macroeconomic conditions. Moreover, confrontation of the GDP growth rate with size and age of the firm produces results that are consistent with the interpretation that the smaller and the younger are the most impacted by macroeconomic conditions. The robust findings allowed the postulation of a new framework that best represents the relationship between the GDP growth rate and small business survival, which is proposed for investigating, analyzing and interpreting such a relationship, being it either central to the study or included only as a control. Also, many predictions from the findings or from interpretations of the findings were also generated. Finally, this framework and its predictions were used to confront results in the extant literature in search for extra support for the findings and theses of the present study. This effort was successful in view of the fact that the greatest portion of the literature adjusted to the new proposed framework.

The remainder of the working paper unfolds as follows. In Section 2, a quick word is dedicated to the original reference study. Section 3 reports detailed results for the GDP growth rate and the industry growth rate. Section 4 presents an in-depth review of the related literature in search for additional evidence that supports the findings of the analysis on the macroeconomic and sectorial determinants of the small manufacturing enterprises' hazard of exit. Section 5 concludes by summarizing the overall results of the research effort and by addressing main implications for theory, policy making and small business support, and for the management of the very small manufacturing enterprises. Of course, the traditional issues of limitations of the present and suggestions for future enquiries are addressed also in this last section.

\section{THE REFERENCE STUDY}

The reference study is described in far more details, comparisons, explanations e justifications in Barbosa (2009). However, interested readers may find that, for the purposes of this article, the version presented in Barbosa (2016), which abbreviates the conventional analyses on the determinants of small business survival, may be sufficient as a reference. Barbosa (2016b)'s working paper on the relationships between, on the one hand, size, growth and age of the firm and, on the other hand, small business survival may be of some help, but it is not essential for the understanding of any part of this study.

It only suffices here to define the variables that are introduced in the present analyses. These are the measures concerning the macroeconomic and sectorial environments of the studied small manufacturing enterprises. Then, first, data for the GDP growth rate and for the 3-yearlagged GDP growth rate were taken from IBGE, under the heading "Produto Interno Bruto (PIB) variação em volume (\%)", available from the website http://www.ibge.gov.br/series_estatisticas. Data on the unemployment rate were taken from the website https://brasilfatosedados.wordpress.com/, which acknowledges credit to IBGE. The scale of the manufacturing sector performance was constructed by taking the algebraic difference between the percentage variation in employment and the percentage variation in payroll for each year of the survivorship follow-up and each one of the three manufacturing sectors studied in this work. Data were taken from FIEMG, Federação das Indústrias de Minas Gerais, so that they are not national, but state level. Data for the last variable, that is, the manufacturing sector sales growth rate were taken from the same source, that is, the state trade association. 
Binary variables were also used to estimate the effects of economic conditions in each of the years of the follow-up on survivorship. Results will be reported in the next part of the work on only the one that is statistically significant in the hazard rate regression analyses. It is set equal to one for failures taking place in the year 1998 and zero otherwise.

Unfortunately, the reference study does not have data on the industry entry rate. This would be invaluable in the reviews of Subsection 4.

3. RESULTS WITH THE MACROECONOMIC AND SECTORIAL AGGREGATES AND POSTULATION OF A REFERENCE FRAMEWORK FOR INVESTIGATING, ANALYZING AND INTERPRETING THE RELATIONSHIPS BETWEEN THESE COVARIATES AND SMALL BUSINESS SURVIVAL

In Panels 1 and 2 of the Table I, auxiliary equations (1) and (4) report results for the fitting of the GDP growth rate and the manufacturing sales growth rate in the monotonic specification employed by all researchers in the whole of the empirical literature that either investigates the impact of these macroeconomic aggregates on the small enterprises' survival prospects or control for their effects. The signs of the estimated coefficients are negative, as expected, but marginally statistically significant for the GDP growth rate and totally statistically insignificant for the manufacturing sector sales growth rate. The fitting of the quadratic specification, which is the choice of all researchers when allowing for non-linear effects of other investigated determinants, such the size of the firm, produces a result strikingly different, that is, highly statistically significant parameter estimates of the adjustment of the specification to a U-shaped relationship between both aggregates, on the one hand, and the small firms' failure likelihood, on the other. This is shown in auxiliary equations (2) and (5). Auxiliary equations (3) and (6) show that the fitting can be further improved by the use of other power combinations.

The auxiliary equations in Panel 3 are exhibited only to demonstrate the superior power of the GDP growth rate over the manufacturing sector sales growth rate to explain variations in the small manufacturing enterprises' hazard of exit. The other external determinants of exit studied in the research of reference are added to the analyses. In all different specifications the z-statistics for the GDP growth rate are higher than those for the manufacturing sector sales growth rate. At final, in auxiliary equation (10), the manufacturing sector sales growth rate loses all statistical significance when all variables enter together the same specification. As the manufacturing sector sales growth rate is not bivariately correlated with any of the other variables, as can be seen in Appendix II, only a multivariate analysis like the one in Panel 3 can reveal that in fact it is actually correlated with the GDP growth rate and at least with one of the other variables.

In special, auxiliary equation (7) in Panel 3 shows that the artificially fitting of a monotonic specification of the GDP growth rate generates a highly statistically significant coefficient estimate that takes up the traditional negative sign. It is understood here that this means that the actual U-shaped relationship is asymmetric, being that the downward trend is either more numerous in terms of residuals, or more clearly defined as a tendency, with the residuals clustered more closely around a virtual fitting curve, or more inclined, or even all these together. This seems to be in some cases clued by the difference in the z-statistic values between the two terms of the quadratic specification. In the case of the manufacturing sector sales growth rate, in auxiliary equation (5), they are much nearer one another, as compared to the difference in z-statistic values for the GDP growth rate, in auxiliary equation (2). Accordingly, the fitting of the monotonic linear specification produces a coefficient estimate that lacks all statistical significance in the case 


\section{EXTERNAL DETERMINANTS OF SMALL BUSINESS SURVIVAL}

of the manufacturing sector sales growth rate, in equation (4), and not so much so in the case of the GDP growth rate, in auxiliary equation (1).

TABLE I - EXTERNAL DETERMINANTS OF SMALL BUSINESS SURVIVAL PANEL 1

\begin{tabular}{|c|c|c|c|c|c|c|}
\hline \multirow{3}{*}{$\begin{array}{l}\text { Regressors/Independent } \\
\text { Variables }\end{array}$} & \multicolumn{6}{|c|}{ COX PROPORTIONAL HAZARD MODEL } \\
\hline & \multicolumn{6}{|c|}{ Auxiliary Equations } \\
\hline & \multicolumn{2}{|c|}{ (1) } & \multicolumn{2}{|c|}{$(2)$} & \multicolumn{2}{|c|}{ (3) } \\
\hline$(\text { GDP growth rate }+1)^{(1)(1)(1 / 2)+}$ & -0.16 & $(1.77)$ & -1.46 & $(4.90)^{\star * \star}$ & -9.15 & $(5.39)^{\star \star \star}$ \\
\hline$(\text { GDP growth rate }+1)^{(\text {na) }(2)(1)+}$ & n.a. & n.a. & 0.18 & $(4.60)^{\star \star \star}$ & 2.49 & $(5.06)^{\star \star \star}$ \\
\hline$R_{p}^{2}$ & \multicolumn{2}{|c|}{0.05} & \multicolumn{2}{|c|}{0.33} & \multicolumn{2}{|c|}{0.40} \\
\hline LR chi2(1/2/2) & \multicolumn{2}{|c|}{3.05} & \multicolumn{2}{|c|}{$24.37^{\star * *}$} & \multicolumn{2}{|c|}{$31.59^{* \star *}$} \\
\hline \multicolumn{7}{|c|}{ PANEL 2} \\
\hline \multirow{3}{*}{$\begin{array}{c}\text { Regressors/Independent } \\
\text { Variables }\end{array}$} & \multicolumn{6}{|c|}{ COX PROPORTIONAL HAZARD MODEL } \\
\hline & \multicolumn{6}{|c|}{ Auxiliary Equations } \\
\hline & \multicolumn{2}{|c|}{ (4) } & \multicolumn{2}{|c|}{$(5)$} & \multicolumn{2}{|c|}{$(6)$} \\
\hline $\begin{array}{l}\text { (Manufacturing sector sales growth } \\
\text { rate }+30)^{(1)(1)(1 / 2)++}\end{array}$ & $-0.02 \mathrm{e}-1$ & $(0.25)$ & -0.11 & $(4.51)^{\star * \star}$ & -1.38 & $(5.28)^{\star \star \star}$ \\
\hline $\begin{array}{l}\text { (Manufacturing sector sales growth } \\
\text { rate }+30)^{(\text {na) (2) (1) ++ }}\end{array}$ & n.a. & n.a. & $0.01 \mathrm{e}-1$ & $(4.45)^{\star \star *}$ & 0.12 & $(4.81)^{\star \star \star}$ \\
\hline$R_{p}^{2}$ & \multicolumn{2}{|c|}{0.00} & \multicolumn{2}{|c|}{0.25} & \multicolumn{2}{|c|}{0.34} \\
\hline LR chi2(1/2/2) & \multicolumn{2}{|c|}{0.06} & \multicolumn{2}{|c|}{$17.34^{* * *}$} & \multicolumn{2}{|c|}{$25.15^{\star * *}$} \\
\hline
\end{tabular}

PANEL 3

\begin{tabular}{|c|c|c|c|c|c|c|c|c|c|c|}
\hline \multirow{3}{*}{$\begin{array}{l}\text { Regressors/Independent } \\
\text { Variables }\end{array}$} & \multicolumn{10}{|c|}{ COX PROPORTIONAL HAZARD MODEL } \\
\hline & \multicolumn{10}{|c|}{ Auxiliary Equations } \\
\hline & \multicolumn{2}{|c|}{ (7) } & \multicolumn{2}{|c|}{$(8)$} & \multicolumn{2}{|c|}{ (9) } & \multicolumn{2}{|c|}{$(10)$} & \multicolumn{2}{|c|}{$(11)$} \\
\hline$(G D P$ growth rate + 1) (1) (1/2) (2) (na) (2) + & -0.54 & $(3.81)^{\star * *}$ & -7.66 & $(4.06)^{\star \star \star}$ & -0.60 & $(6.01)^{\star * *}$ & n.a. & n.a. & -0.58 & $(5.55)^{\star \star \star}$ \\
\hline$($ GDP growth rate + 1) (na) (1) (3) (na) (3) + & n.a. & n.a. & 2.21 & $(4.15)^{\star \star \star}$ & 0.08 & $(5.86)^{\star \star \star}$ & n.a. & n.a. & 0.08 & $(5.52)^{\star \star \star}$ \\
\hline $\begin{array}{l}\text { (Manufacturing sector sales growth } \\
\text { rate }+30)^{(\text {na) }(1 / 2)(\text { na) (1/2) (1/2) }}+{ }^{++}\end{array}$ & n.a. & n.a. & -1.07 & $(3.05)^{\star *}$ & n.a. & n.a. & -1.02 & $(3.48)^{\star * \star}$ & -0.32 & $(0.94)$ \\
\hline $\begin{array}{l}\text { (Manufacturing sector sales growth } \\
\text { rate }+30)^{(\text {na) (1) (na) (1) (1) ++ }}\end{array}$ & n.a. & n.a. & 0.09 & $(2.91)^{\star *}$ & n.a. & n.a. & 0.09 & $(3.25)^{\star *}$ & 0.03 & $(0.93)$ \\
\hline 3-year-lagged GDP growth rate & -0.42 & $(4.05)^{\star \star *}$ & n.a. & n.a. & -0.64 & $(5.17)^{\star \star *}$ & -0.08 & $(3.34)^{\star \star \star}$ & -0.63 & $(5.02)^{* * *}$ \\
\hline Manufacturing sector performance & -0.11 & $(4.87)^{\star \star *}$ & n.a. & n.a. & -0.14 & $(5.37)^{\star \star *}$ & -0.22 & $(2.63)^{\star *}$ & -0.13 & $(4.17)^{\star \star \star}$ \\
\hline 1998 year dummy & 3.31 & $(4.56)^{\star * \star}$ & n.a. & n.a. & 5.91 & $(5.84)^{\star * *}$ & 2.05 & $(3.47)^{\star \star \star}$ & 5.81 & $(5.64)^{* * *}$ \\
\hline $\mathrm{R}_{\mathrm{p}}^{2}$ & \multicolumn{2}{|c|}{0.60} & \multicolumn{2}{|c|}{0.50} & \multicolumn{2}{|c|}{0.77} & \multicolumn{2}{|c|}{0.57} & \multicolumn{2}{|c|}{0.77} \\
\hline LR chi2(4/5/5/7) & \multicolumn{2}{|c|}{$56.10^{* * *}$} & \multicolumn{2}{|c|}{$42.30^{* * *}$} & \multicolumn{2}{|c|}{$89.86^{* * *}$} & \multicolumn{2}{|c|}{$52.11^{\star \star \star}$} & \multicolumn{2}{|c|}{90.77} \\
\hline
\end{tabular}

Obs: 1) First values in the main body of the table are coefficient estimates; 2) numbers in parentheses are absolute value $\mathrm{z}$-statistics; 3$) *, * *$, and $* * *$ denote statistical significance at the $5 \%, 1 \%$, and $0.1 \%$ levels, respectively 4$)+$ and ++ Adding 1 and 30 respectively was necessary in order to make it possible to extract the square root for the originally negative values; 5) Number events/cases (firms): 46/61.

Some conclusions can already be drawn from the analyses so far. The GDP growth rate has the strongest effect out of all external covariates, even though people tend to think that this macroeconomic aggregate measured at the national level reflects phenomena taking place away 


\section{EVALDO GUIMARÃES BARBOSA}

from the ordinary citizens' day-to-day and the manufacturing sector sales growth rate being measured at the level of the state where the studied enterprises are located. Thus, it is not surprising, provided it is a genuine sample of small firms, that practically no author has come across with the result of lack of statistical significance concerning the GDP growth rate as a determinant of business survival. As it will be seen in the next section, this is a common result with respect to the industry growth rate.

TABLE II - EXTERNAL DETERMINANTS VERSUS FIRM SPECIFIC STRATEGY AND RISK RELATED DETERMINANTS OF SMALL BUSINESS SURVIVAL

\begin{tabular}{|c|c|c|c|c|c|c|c|c|}
\hline \multirow{4}{*}{$\begin{array}{c}\begin{array}{c}\text { Regressors/Independent } \\
\text { Variables }\end{array} \\
(\text { GDP growth rate + 1) (na) (1) (1) (2)+ }\end{array}$} & \multicolumn{8}{|c|}{ COX PROPORTIONAL HAZARD MODEL } \\
\hline & \multirow{2}{*}{\multicolumn{2}{|c|}{ Main Equation (1) }} & \multicolumn{6}{|c|}{ Auxiliary Equations } \\
\hline & & & \multicolumn{2}{|c|}{$(2)$} & \multicolumn{2}{|c|}{ (3) } & \multicolumn{2}{|c|}{$(4)$} \\
\hline & n.a. & n.a. & -0.42 & $(1.99)^{*}$ & -2.04 & $(2.90)^{\star *}$ & -0.43 & $(2.77)^{\star *}$ \\
\hline$($ GDP growth rate +1$)($ na) (na) (2) (3) + & n.a. & n.a. & n.a. & n.a. & 0.21 & $(2.51)^{\star}$ & 0.05 & $(2.68)^{\star *}$ \\
\hline 3-year-lagged GDP growth rate & -0.41 & $(3.26)^{\star *}$ & -0.65 & $(3.57)^{\star * *}$ & -0.77 & $(3.81)^{\star * *}$ & -0.82 & $(3.75)^{\star \star \star}$ \\
\hline Manufacturing sector performance & -0.11 & $(3.43)^{\star \star *}$ & -0.14 & $(3.71)^{* * *}$ & -0.15 & $(3.73)^{\star * \star}$ & -0.15 & $(3.77)^{\star \star \star}$ \\
\hline 1998 year dummy & 6.36 & $(4.78)^{\star * \star}$ & 7.23 & $(5.06)^{\star * *}$ & 9.01 & $(4.82)^{\star * \star}$ & 9.37 & $(4.72)^{\star \star \star}$ \\
\hline Net working capital & -4.84 & $(4.11)^{\star \star \star}$ & -4.03 & $(3.28)^{\star *}$ & -4.10 & $(3.14)^{\star *}$ & -4.18 & $(3.21)^{\star *}$ \\
\hline Total Financial Leverage & -10.31 & $(5.22)^{\star \star \star}$ & -7.79 & $(3.39)^{\star \star *}$ & -8.05 & $(3.17)^{\star *}$ & -8.34 & $(3.28)^{* *}$ \\
\hline $\begin{array}{l}\text { Medium- and Long-term Financial } \\
\text { Leverage }\end{array}$ & 13.54 & $(3.78)^{\star \star *}$ & 14.64 & $(3.93)^{\star * \star}$ & 8.91 & $(2.03)^{*}$ & 9.41 & $(2.17)^{\star}$ \\
\hline Profitability & -0.66 & $(3.32)^{\star \star *}$ & -0.50 & $(2.38)^{*}$ & -0.59 & $(2.68)^{\star *}$ & -0.58 & $(2.67)^{\star *}$ \\
\hline Operational cycle $\mathrm{e}^{1 / 3}$ & -25.92 & $(3.75)^{\star * \star}$ & -24.91 & $(3.66)^{\star * *}$ & -23.93 & $(3.39)^{\star * *}$ & -23.80 & $(3.41)^{\star \star \star}$ \\
\hline Operational cycle ${ }^{1 / 2}$ & 9.01 & $(4.04)^{\star \star \star}$ & 8.51 & $(3.86)^{\star * *}$ & 8.15 & $(3.55)^{\star \star *}$ & 8.16 & $(3.59)^{\star \star \star}$ \\
\hline Automation degree & -6.52 & $(5.27)^{\star * *}$ & -6.58 & $(5.24)^{\star * *}$ & -5.28 & $(3.82)^{\star * *}$ & -5.49 & $(4.08)^{\star * \star}$ \\
\hline Automation degree $^{2}$ & 1.27 & $(5.55)^{\star * *}$ & 1.21 & $(5.23)^{\star * *}$ & 1.02 & $(3.99)^{\star * *}$ & 1.057 & $(4.23)^{\star * \star}$ \\
\hline Machinery/fixed assets ratio ${ }^{4}$ & -63.64 & $(4.62)^{\star * *}$ & -64.40 & $(4.55)^{\star * *}$ & -48.09 & $(3.13)^{\star *}$ & -49.05 & $(3.21)^{* *}$ \\
\hline Machinery/fixed assets ratio 5 & 73.64 & $(4.97)^{\star * *}$ & 73.25 & $(4.81)^{\star \star *}$ & 56.79 & $(3.46)^{* \star *}$ & 57.83 & $(3.55)^{\star * \star}$ \\
\hline Corporate diversification & -0.04 & $(3.50)^{\star * *}$ & -0.03 & $(3.12)^{\star *}$ & -0.03 & $(3.03)^{\star *}$ & -0.03 & $(3.17)^{\star *}$ \\
\hline Market concentration & -0.15 & $(3.98)^{\star * \star}$ & -0.15 & $(3.82)^{* * *}$ & -0.10 & $(2.62)^{\star *}$ & -0.10 & $(2.43)^{* *}$ \\
\hline Market concentration ${ }^{2}$ & $0.14 \mathrm{e}-2$ & $(3.91)^{\star * *}$ & $0.13 e-2$ & $(3.35)^{\star * *}$ & $0.88 \mathrm{e}-3$ & $(2.19)^{*}$ & $0.85 \mathrm{e}-3$ & $(2.05)^{*}$ \\
\hline Client concentration & 0.06 & $(5.45)^{\star * *}$ & 0.06 & $(5.40)^{\star * *}$ & 0.06 & $(4.82)^{\star \star *}$ & 0.06 & $(4.96)^{\star \star \star}$ \\
\hline Sales concentration in big clients & 0.10 & $(5.99)^{\star \star \star}$ & 0.10 & $(5.66)^{\star \star *}$ & 0.10 & $(5.30)^{\star \star *}$ & 0.10 & $(5.36)^{\star \star \star}$ \\
\hline Sales unpredictability & 0.48 & $(3.94)^{\star * *}$ & 0.41 & $(3.27)^{\star *}$ & 0.30 & $(2.19)^{*}$ & 0.31 & $(2.27)^{*}$ \\
\hline Entrepreneur's Risk Tolerance & 2.05 & $(6.01)^{\star * *}$ & 1.82 & $(5.03)^{\star * *}$ & 1.63 & $(4.09)^{\star * *}$ & 1.66 & $(4.14)^{\star * \star}$ \\
\hline Market concentration X Operational cycle & $-0.36 e-3$ & $(2.80)^{\star *}$ & $-0.25 \mathrm{e}-3$ & $(1.76)$ & $-0.25 e-3$ & $(1.76)$ & $-0.27 e-3$ & $(1.87)$ \\
\hline $\begin{array}{l}\text { Sales concentration in big clients } X \\
\text { Machinery/fixed assets ratio }\end{array}$ & -0.10 & $(4.88)^{\star * *}$ & -0.10 & $(4.56)^{\star * *}$ & -0.11 & $(4.45)^{\star \star *}$ & -0.11 & $(4.51)^{\star \star \star}$ \\
\hline $\mathrm{R}_{\mathrm{p}}^{2}$ & \multicolumn{2}{|c|}{0.89} & \multicolumn{2}{|c|}{0.89} & \multicolumn{2}{|c|}{0.90} & \multicolumn{2}{|c|}{0.90} \\
\hline LR chi2(22/23/24/24) & \multicolumn{2}{|c|}{$132.63^{\star * *}$} & \multicolumn{2}{|c|}{$136.69^{\star * *}$} & \multicolumn{2}{|c|}{$143.20^{\star * *}$} & \multicolumn{2}{|c|}{$142.27^{* * *}$} \\
\hline
\end{tabular}

Obs: 1) First values in the main body of the table are coefficient estimates; 2) numbers in parentheses are absolute value $\mathrm{z}$-statistic; 3) $* * *$, and $* * *$ denote statistical significance at the $5 \%, 1 \%$, and $0.1 \%$ levels, respectively; 4) + Adding 1 was necessary in order to make it possible to extract the square root for the originally negative values; 5 ) Number events/cases (firms): 46/61.

For the remaining part of this section the analyses will consider only the GDP growth rate, in view of its higher importance and because the manufacturing sector sales growth rate does produce the same results. So, beforehand it may be stated that for the small manufacturing enterprises it is the macroeconomic conditions that matter the most, even though the GDP growth 
rate is measured at the national level and the manufacturing sector sales growth rate is measured at the state and industry levels.

In Table II, main equation (1) is taken from the reference study (Barbosa 2009; Barbosa 2016), with the addition of the manufacturing sector performance, since now the requirement of being statistically significant at least at the $0.1 \%$ level to make part of the final model has been relaxed. Chart 01 exhibits the plotting of the martingale residuals from main equation (1) against the values of the GDP growth rate (and Chart 02 for the manufacturing sector sales growth rate). Auxiliary equation (2) reports results for the fitting of the GDP growth rate in the monotonic specification employed by all researchers in the whole of the empirical literature that either investigates the impact of this macroeconomic aggregate on the small enterprises' survival prospects or control for it. The sign of the estimated coefficient is negative, as expected, but marginally statistically significant. The fitting of the quadratic specification, which is the choice of all researchers when allowing for non-linear effects of the investigated determinant, such the size of the firm, produces a different result, that is, statistically significant parameter estimates of the adjustment of the specification to a U-shaped relationship between the aggregate and the small firms' failure likelihood. This is shown in auxiliary equation (3). Auxiliary equation (4) shows that the fitting can be further improved, in terms of equilibrium between the z-statistics, by the use of other power combinations.
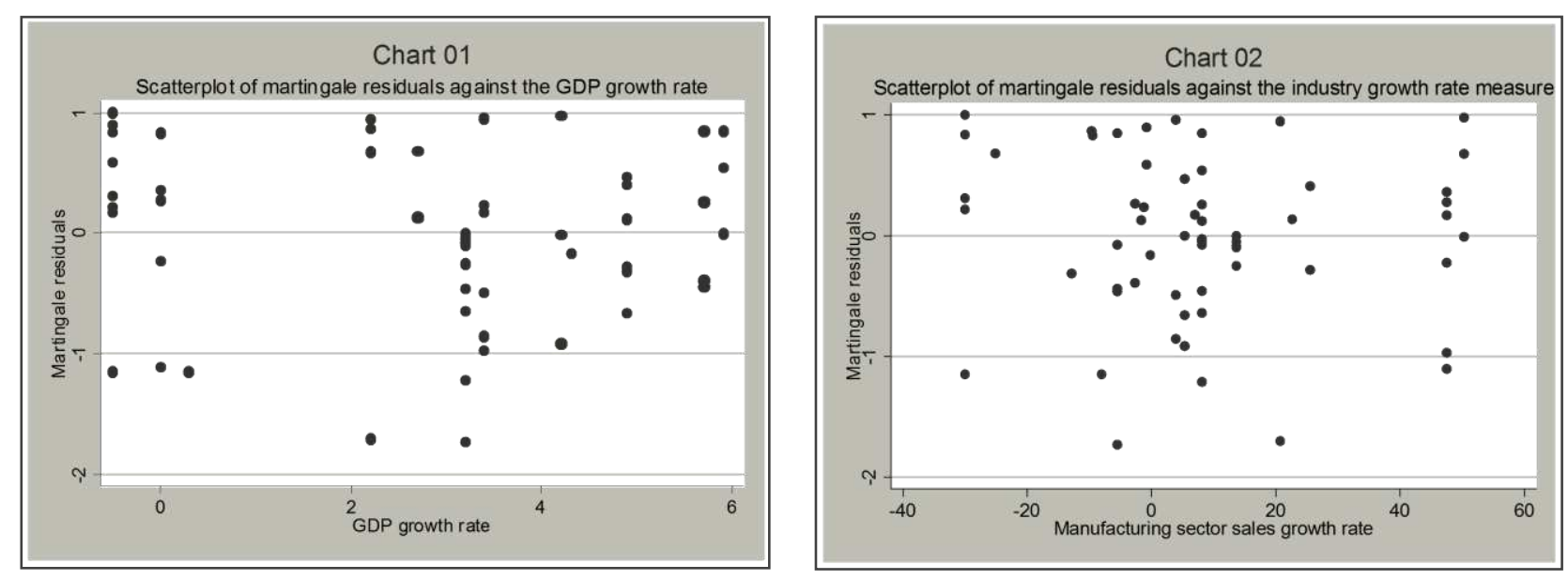

Comparing results in main equation (1) with results in auxiliary equation (4) makes it possible to see that the introduction of the GDP growth rate into the main equation (1) does not have a large impact on the strategy and risk related variables. Reduction in their coefficients and zstatistics are only mild. On the other hand, coefficients and z-statistics belonging to the GDP growth variable are low compared to their size in Table I, Panels 1 and 3. This is consistent with the interpretation that the state of the macroeconomic environment strongly determines that small enterprises will exit, but what determines which ones will exit is the strategies set at the level of the small enterprises and the risks they individually face. However, whether the successful choices are conscious or the corresponding enterprises are selected in the way predicted by the organizational ecology approach remains unsettled.

Table III reports results from an experiment to see which firms are the most impacted during swings in the macroeconomic environment, assuming that the magnitude of loss in the 
absolute value of the z-statistic of a variable as a result of the additional introduction of another covariate into the equation means how much they are capturing the same effects. So, Column $\%$ of loss shows the percentage fall in z-statistic for every variable when the GDP growth rate specification is introduced into the analysis, that is, from the second column to third one in Table III. It is easy to see that the great losses are at the magnitude of 48, market concentration, 43, medium- and long-term financial leverage, 42, sales unpredictability, 39, market concentration again, 37, total financial leverage, 33, one of the interactions, and 31, entrepreneur's risk tolerance. That is, consistent with the common sense, the enterprises that are most impacted are the ones that have more debt, medium- and long-term debt and total debt as well, and that are facing higher risks, unpredictability of sales and how bold their owner-managers are. Against marketing theory, the most impacted variable has much to do with the allegation that the small firm would be shielded by operating in niche markets, that is, geographic market concentration.

TABLE III - EXTERNAL DETERMINANTS VERSUS FIRM SPECIFIC STRATEGY AND RISK RELATED DETERMINANTS OF SMALL BUSINESS SURVIVAL

\begin{tabular}{|c|c|c|c|c|}
\hline \multirow{3}{*}{$\begin{array}{c}\text { Regressors/Independent } \\
\text { Variables }\end{array}$} & \multicolumn{4}{|c|}{ COX PROPORTIONAL HAZARD MODEL } \\
\hline & \multicolumn{2}{|c|}{ Z-statistics from Table II } & \multirow[b]{2}{*}{$\begin{array}{l}\% \text { of loss in z- } \\
\text { statistics }\end{array}$} & \multirow[b]{2}{*}{$\begin{array}{c}\text { Ranking in } \% \text { of } \\
\text { loss }\end{array}$} \\
\hline & $\begin{array}{l}\text { From Main } \\
\text { Equation (1) }\end{array}$ & $\begin{array}{c}\text { From Auxiliary } \\
\text { Equation (4) }\end{array}$ & & \\
\hline Net working capital & $(4.11)^{\star * *}$ & $(3.21)^{\star *}$ & 22 & 11 \\
\hline Total Financial Leverage & $(5.22)^{\star * \star}$ & $(3.28)^{\star *}$ & 37 & 5 \\
\hline Medium- and Long-term Financial Leverage & $(3.78)^{* * *}$ & $(2.17)^{*}$ & 43 & 2 \\
\hline Profitability & $(3.32)^{* * *}$ & $(2.67)^{\star *}$ & 20 & 12 \\
\hline Operational cycle ${ }^{1 / 3}$ & $(3.75)^{\star * *}$ & $(3.41)^{\star * *}$ & 9 & 14 \\
\hline Operational cycle $\mathrm{e}^{1 / 2}$ & $(4.04)^{\star * *}$ & $(3.59)^{* * *}$ & 11 & 13 \\
\hline Automation degree & $(5.27)^{* * *}$ & $(4.08)^{* * *}$ & 23 & 10 \\
\hline Automation degree $^{2}$ & $(5.55)^{* * *}$ & $(4.23)^{* * *}$ & 24 & 9 \\
\hline Machinery/fixed assets ratio 4 & $(4.62)^{* * *}$ & $(3.21)^{\star *}$ & 31 & 7 \\
\hline Machinery/fixed assets ratio ${ }^{5}$ & $(4.97)^{\star * *}$ & $(3.55)^{* * *}$ & 29 & 8 \\
\hline Corporate diversification & $(3.50)^{\star * *}$ & $(3.17)^{\star *}$ & 9 & 14 \\
\hline Market concentration & $(3.98)^{* * *}$ & $(2.43)^{\star *}$ & 39 & 4 \\
\hline Market concentration $^{2}$ & $(3.91)^{* * *}$ & $(2.05)^{*}$ & 48 & 1 \\
\hline Client concentration & $(5.45)^{* * *}$ & $(4.96)^{* * *}$ & 9 & 14 \\
\hline Sales concentration in big clients & $(5.99)^{\star \star \star}$ & $(5.36)^{* * *}$ & 11 & 13 \\
\hline Sales unpredictability & $(3.94)^{* * *}$ & $(2.27)^{*}$ & 42 & 3 \\
\hline Entrepreneur's Risk Tolerance & $(6.01)^{* * *}$ & $(4.14)^{* * *}$ & 31 & 7 \\
\hline Market concentration X Operational cycle & $(2.80)^{* *}$ & $(1.87)$ & 33 & 6 \\
\hline Sales concentration in big clients X Machinery/fixed assets ratio & $(4.88)^{\star * *}$ & $(4.51)^{* * *}$ & 8 & 15 \\
\hline
\end{tabular}

Obs: 1) *,**, and *** denote statistical significance at the 5\%, 1\%, and $0.1 \%$ levels, respectively; 2) Number events/cases (firms): 46/61.

The last column was built to ease visualization of the greater losers. To see whether or not the above finding comes from the fact that high percentage figures are associated with low figures for the base from which the percentage figures are calculated, it was calculated the bivariate correlation coefficient between the second column and the fourth. As it was only $r=-0.13$, that possibility was discarded.

The odd auxiliary equations in Table IV are brought from Barbosa (2016b)'s working paper, only that the variable manufacturing sector performance is added and 19 regressors/independent variables are omitted, because they are not of interest in the following analyses and for the sake of space. In all these equations, the measures of size, growth and age of 


\section{EXTERNAL DETERMINANTS OF SMALL BUSINESS SURVIVAL}

the firm are statistically significant. When the GDP growth rate is introduced into the equations, as can be seen in the even equations, practically all measures of size, growth and age of the firm lose all their statistical significance. The only exception is the growth interaction in auxiliary equations (9) and (10). These results and the findings of many of the reviewed studies that the larger enterprises do not suffer so much from the macroeconomic conditions are consistent with the idea of the smaller enterprises being the great "victims" of downturns of the economy and, from the results of this study, of the upturns as well.

TABLE IV - EXTERNAL VERSUS SIZE, GROWTH AND AGE OF THE FIRM DETERMINANTS OF SMALL BUSINESS SURVIVAL

PANEL 1

\begin{tabular}{|c|c|c|c|c|c|c|c|c|}
\hline \multirow{3}{*}{$\begin{array}{c}\text { Regressors/Independent } \\
\text { Variables }\end{array}$} & \multicolumn{8}{|c|}{ COX PROPORTIONAL HAZARD MODEL } \\
\hline & \multicolumn{8}{|c|}{ Auxiliary Equations } \\
\hline & \multicolumn{2}{|c|}{ (1) } & \multicolumn{2}{|c|}{$(2)$} & \multicolumn{2}{|c|}{$(3)$} & \multicolumn{2}{|c|}{$(4)$} \\
\hline$($ GDP growth rate + 1) (na) (2) (na) (2) & n.a. & n.a. & -0.71 & $(4.84)^{\star \star *}$ & n.a. & n.a. & -0.69 & $(4.85)^{* * *}$ \\
\hline$(\text { GDP growth rate }+1)^{(\text {na) }}(3)($ na) $(3)$ & n.a. & n.a. & 0.09 & $(4.79)^{\star * \star}$ & n.a. & n.a. & 0.09 & $(4.78)^{\star \star *}$ \\
\hline 3-year-lagged GDP growth rate & -0.42 & $(3.93)^{\star * *}$ & -0.96 & $(5.16)^{\star \star *}$ & -0.23 & $(2.41)^{*}$ & -0.91 & $(4.62)^{* \star *}$ \\
\hline Manufacturing sector performance & -0.08 & $(3.09)^{\star \star}$ & -0.16 & $(4.59)^{\star * \star}$ & -0.08 & $(3.00)^{\star *}$ & -0.17 & $(4.61)^{\star \star *}$ \\
\hline 1998 year dummy & 4.35 & $(3.80)^{\star * \star}$ & 9.81 & $(4.84)^{\star \star *}$ & 3.18 & $(2.87)^{\star *}$ & 9.04 & $(4.56)^{* * \star}$ \\
\hline Ln total assets 4 & $-0.46 e-2$ & $(2.96)^{* \star}$ & $-0.19 e-2$ & $(1.14)$ & n.a. & n.a. & n.a. & n.a. \\
\hline Ln total assets ${ }^{5}$ & $0.48 \mathrm{e}-3$ & $(2.91)^{\star \star}$ & $0.21 \mathrm{e}-3$ & $(1.18)$ & n.a. & n.a. & n.a. & n.a. \\
\hline$(\text { Ln sales) })^{4}$ & n.a. & n.a. & n.a. & n.a. & $-0.50 e-3$ & $(3.30)^{* *}$ & $-0.20 e-3$ & $(1.22)$ \\
\hline$(\text { Ln sales })^{5}$ & n.a. & n.a. & n.a. & n.a. & $0.18 \mathrm{e}-4$ & $(3.28)^{\star *}$ & $7.53 e-06$ & $(1.23)$ \\
\hline $\mathrm{R}_{\mathrm{p}}^{2}$ & \multicolumn{2}{|c|}{0.78} & \multicolumn{2}{|c|}{0.87} & \multicolumn{2}{|c|}{0.78} & \multicolumn{2}{|c|}{0.87} \\
\hline LR chi2(21/23/20/22) & \multicolumn{2}{|c|}{$92.37^{* * *}$} & \multicolumn{2}{|c|}{$122.84^{* * *}$} & \multicolumn{2}{|c|}{$91.72^{* * *}$} & \multicolumn{2}{|c|}{$122.88^{* * *}$} \\
\hline
\end{tabular}

PANEL 2

\begin{tabular}{|c|c|c|c|c|c|c|c|c|}
\hline \multirow{3}{*}{$\begin{array}{c}\text { Regressors/Independent } \\
\text { Variables }\end{array}$} & \multicolumn{8}{|c|}{ COX PROPORTIONAL HAZARD MODEL } \\
\hline & \multicolumn{8}{|c|}{ Auxiliary Equations } \\
\hline & \multicolumn{2}{|c|}{$(5)$} & \multicolumn{2}{|c|}{ (6) } & \multicolumn{2}{|c|}{$(7)^{\#}$} & \multicolumn{2}{|c|}{$(8)^{\#}$} \\
\hline (GDP growth rate) ${ }^{(\text {na) (2) (na) (2) }}$ & n.a. & n.a. & -0.62 & $(3.84)^{\star * *}$ & n.a. & n.a. & -0.72 & $(4.11)^{\star \star \star}$ \\
\hline (GDP growth rate) (na) (3) (na) (3) & n.a. & n.a. & 0.07 & $(3.47)^{\star \star \star}$ & n.a. & n.a. & 0.09 & $(3.81)^{* * *}$ \\
\hline 3-year-lagged GDP growth rate & -0.20 & $(-2.02)^{*}$ & -0.96 & $(4.26)^{\star * \star}$ & -0.35 & $(2.99)^{* *}$ & -1.10 & $(4.96)^{* * *}$ \\
\hline Manufacturing sector performance & -0.11 & $(3.88)^{* * *}$ & -0.17 & $(4.64)^{\star * *}$ & -0.10 & $(3.06)^{* *}$ & -0.18 & $(4.31)^{* * *}$ \\
\hline 1998 year dummy & 5.09 & $(4.11)^{\star \star \star}$ & 9.33 & $(4.80)^{\star \star \star}$ & 3.55 & $(3.54)^{\star \star \star}$ & 9.38 & $(4.90)^{* \star *}$ \\
\hline Employment $^{1 / 3}$ & 12.05 & $(2.57)^{\star}$ & 6.94 & $(1.24)$ & n.a. & n.a. & n.a. & n.a. \\
\hline employment $t^{1 / 2}$ & -4.13 & $(2.57)^{\star}$ & -2.21 & $(1.15)$ & n.a. & n.a. & n.a. & n.a. \\
\hline $\mathrm{Age}^{2}$ & n.a. & n.a. & n.a. & n.a. & $0.52 \mathrm{e}-2$ & $(2.31)^{*}$ & $-0.16 e-2$ & $(0.47)$ \\
\hline $\mathrm{Age}^{3}$ & n.a. & n.a. & n.a. & n.a. & $-0.10 e-3$ & $(2.08)^{*}$ & $0.71 \mathrm{e}-4$ & $(0.93)$ \\
\hline$R_{p}^{2}$ & \multicolumn{2}{|c|}{0.82} & \multicolumn{2}{|c|}{0.88} & \multicolumn{2}{|c|}{0.83} & \multicolumn{2}{|c|}{0.89} \\
\hline LR chi2(21/23/23/25) & \multicolumn{2}{|c|}{$103.50^{* * *}$} & \multicolumn{2}{|c|}{$129.05^{\star * *}$} & \multicolumn{2}{|c|}{$107.92^{\star \star *}$} & \multicolumn{2}{|c|}{$134.55^{* * *}$} \\
\hline
\end{tabular}

The foregoing allows the postulation of a new framework that best represents the relationship between the GDP growth rate and small business survival, which is proposed for investigating, analyzing and interpreting such a relationship, being it either central to the study or included only as a control. Such framework is built upon two realizations. The first is that the relationship between the GDP growth rate and small business survival is binomial, U-shaped. A linear fitting is artificial, although, as a rule, produces a negative relationship. The second realization is that a quadratic specification is not always the best fit for the relationship. The U- 
shaped relationship is not symmetrical. It is so much so that this is the reason why the linear fitting produces, as a rule, a negative relationship. A binomial specification with a combination of powers either smaller than the unit or greater than the square may fit better the regression.

PANEL 3

\begin{tabular}{|c|c|c|c|c|c|c|c|c|}
\hline \multirow{3}{*}{$\begin{array}{l}\text { Regressors/Independent } \\
\text { Variables }\end{array}$} & \multicolumn{8}{|c|}{ COX PROPORTIONAL HAZARD MODEL } \\
\hline & \multicolumn{8}{|c|}{ Auxiliary Equations } \\
\hline & \multicolumn{2}{|c|}{ (9) } & \multicolumn{2}{|c|}{ (10) } & \multicolumn{2}{|c|}{$(11)^{\#}$} & \multicolumn{2}{|c|}{$(12)^{\#}$} \\
\hline$(G D P \text { growth rate }+1)^{(\text {na) (2) (na) (2) }}{ }^{+}$ & n.a. & n.a. & -0.42 & $(2.70)^{\star *}$ & n.a. & n.a. & -0.86 & $(4.94)^{\star \star \star}$ \\
\hline$\left(\right.$ GDP growth rate+1) (na) (3) (na) (3) ${ }^{+}$ & n.a. & n.a. & 0.05 & $(2.35)^{*}$ & n.a. & n.a. & 0.11 & $(4.62)^{\star * \star}$ \\
\hline 3-year-lagged GDP growth rate & -0.43 & $(3.10)^{\star *}$ & -0.99 & $(4.31)^{\star * *}$ & -0.49 & $(4.18)^{\star * *}$ & -1.28 & $(5.69)^{\star * *}$ \\
\hline Manufacturing sector performance & -0.17 & $(3.87)^{\star \star *}$ & -0.21 & $(4.43)^{\star \star *}$ & -0.08 & $(2.79)^{\star *}$ & -0.22 & $(4.98)^{\star \star \star}$ \\
\hline 1998 year dummy & 5.11 & $(4.95)^{\star * \star}$ & 8.54 & $(5.06)^{* \star *}$ & 3.28 & $(3.03)^{\star *}$ & 9.67 & $(5.01)^{\star * *}$ \\
\hline (Ln total assets) ${ }^{4}$ & n.a. & n.a. & n.a. & n.a. & $-0.72 e-2$ & $(3.46)^{\star * *}$ & $-0.42 e-2$ & $(1.82)$ \\
\hline$(\text { Ln total assets })^{5}$ & n.a. & n.a. & n.a. & n.a. & $0.74 \mathrm{e}-3$ & $(3.37)^{\star * *}$ & $0.45 \mathrm{e}-3$ & $(1.87)$ \\
\hline $\mathrm{Age}^{2}$ & n.a. & n.a. & n.a. & n.a. & $0.87 \mathrm{e}-2$ & $(2.85)^{* *}$ & $-0.49 e-2$ & $(1.30)$ \\
\hline $\mathrm{Age}^{3}$ & n.a. & n.a. & n.a. & n.a. & $-0.19 \mathrm{e}-3$ & $(2.90)^{\star *}$ & $0.13 e-3$ & $(1.53)$ \\
\hline $\begin{array}{l}\text { [(GrowthXSales VariabilityXEntrepreneur's } \\
\text { Risk Tolerance)+100](1) (1) (1/2) (2) }{ }^{+++}\end{array}$ & -3.48 & $(4.42)^{\star \star \star}$ & -3.51 & $(4.09)^{* \star *}$ & $-0.67 e-3$ & $(3.47)^{\star \star *}$ & $-0.52 \mathrm{e}-3$ & $(2.51)^{*}$ \\
\hline $\begin{array}{l}\text { [(GrowthXSales VariabilityXEntrepreneur's } \\
\quad \text { Risk Tolerance)+100](na) (2) (1) (3)+++ }\end{array}$ & 0.16 & $(4.23)^{\star \star *}$ & 0.16 & $(3.80)^{\star \star *}$ & $2.71 e-06$ & $(3.49)^{\star \star *}$ & $2.16 \mathrm{e}-06$ & $(2.57)^{*}$ \\
\hline$R_{p}^{2}$ & \multicolumn{2}{|c|}{0.90} & \multicolumn{2}{|c|}{0.92} & \multicolumn{2}{|c|}{0.79} & \multicolumn{2}{|c|}{0.89} \\
\hline LR chi2(23/25/24/26) & \multicolumn{2}{|c|}{$137.66^{* * *}$} & \multicolumn{2}{|c|}{$151.27^{\star \star *}$} & \multicolumn{2}{|c|}{$92.69^{* * *}$} & \multicolumn{2}{|c|}{$132.21^{* * *}$} \\
\hline
\end{tabular}

Obs: 1) First values in the main body of the table are coefficient estimates; 2) numbers in parentheses are absolute value $\mathrm{z}$-statistics; 3 ) * **, and *** denote statistical significance at the $5 \%, 1 \%$, and $0.1 \%$ levels, respectively; 4) \# without case 29, which is an influential outlier; 5) + and +++ Adding 1 and 100 respectively was necessary in order to make it possible to extract the square root for the originally negative values; 6) Number events/cases (firms): $46 / 61$.

The same above postulates apply to the industry growth rate, being that its U-shaped relationship with the small businesses' hazard of exit derives to a great extent from that between the GDP growth rate with the small firms' hazard of exit. Thus, the fitting of both binomial specifications in the same equation will probably result in that between the industry growth rate and the small enterprises' failure probability being statistically insignificant, as the one between the GDP growth rate and the small firms' hazard of exit is stronger.

The simultaneous fitting of the linear specifications of the GDP growth rate and the industry growth rate will probably result in both being statistically significant, being that the GDP growth rate will be negatively signed, that is, capturing the downtrend of the real U-shaped relationship with the small businesses' hazard of exit, and the industry growth rate will be positively signed, that is, capturing the uptrend of the real U-shaped relationship between either the GDP growth rate or the industry growth rate with the small enterprises' hazard rate.

The above mentioned U-shaped relationships are consistent with the interpretation that they are produced by high entry of new small firms during both downturns and upturns of the economy, being in the former case by necessity entrepreneurs and the latter by opportunity entrepreneurs. Of course the downs in the economy by themselves promote the failure of both incumbent and new firms. But even so there should be a high correlation, between both the national entry rates and the industry entry rates and the GDP growth rate, the industry growth rate, (non-linear in these cases) and the hazard of exit (linear in this case). Their linear fitting together with that of either the GDP growth rate or the industry growth rate will probably capture either its own real relationship with the small firms' hazard of exit or the uptrend of the actual U-shaped 


\section{EXTERNAL DETERMINANTS OF SMALL BUSINESS SURVIVAL}

relationship between either the GDP growth rate or the industry growth rate with the small concerns' hazard of exit. Fitting the linear specification of the entry rate together with the quadratic specification of either the GDP growth rate or the industry growth rate will probably result in the entry rate being statistically insignificant.

The entry rate can be viewed as an absolute value version of either the GDP growth rate or the industry growth rate. Thus, a high bivariate correlation coefficient should be found between the entry rate and the absolute values of either the GDP growth or the industry growth rate.

There should be also a U-shaped relationship between either the initial GDP growth rate or the initial industry growth rate and the small firms' hazard of exit. Such prediction is built upon the understanding that it is during both the downward swings and the booms of the economy that bad start-ups concentrate. So, these bad start-ups will inflate the small businesses' future failure rate.

Such a theoretical framework and its predictions are important in that compliance with them in studies that involve the relationship between the GDP growth rate and small business survival, promises the obtaining of more realistic overall results. The obtaining of better overall results can be attributable to 1) a more correct econometric representation of the relationships between the GDP growth rate and the survival of small businesses and also 2) to the fact that such more correct specification can greatly increase the quality of the results pertaining to all other studied effects.

\section{CORROBORATIVE EVIDENCE FROM THE EXTANT LITERATURE}

Amazingly, empirical studies do not report attempts to fit non-linear specifications for either the GDP growth rate or the industry growth rate. Thus, direct evidence strictly speaking is not found in the empirical literature on small business survival. A way found to use the previous empirical studies as a source of corroborative evidence is to look at their results, mainly the disparate, awkward, embarrassing, unexpected and unacceptable ones, to see whether they are in accordance with the predictions of the frame of reference postulated in Section 3. An implication of this is that weird results signalize that correction is needed in accordance with the postulated frame of reference.

\subsection{THE GDP GROWTH RATE}

One prediction of the new postulated framework is that the negative association between the GDP growth rate and the hazard of exit is the most common outcome to be obtained by studies fitting a monotonic specification. Table $\mathrm{V}$ exhibits the previous results from the small businesses' empirical literature according to the nature of the finding. The counting is 11 for the decreasing relationship, one for the increasing and one for no relationship. The first prediction holds, but it is evidence also in favor of the prevalent conventional frame of reference. So, the analysis will proceed to check for extra evidence in the studies that have found a negative relationship of the GDP growth rate with the hazard of exit.

Strictly adhering to the predictions of the new proposed framework, all studies that have found a negative association between the GDP growth rate and the hazard of exit at the same time that have found a positive association between either the industry growth rate or the industry entry 
rate and the hazard of exit carry with them extra evidence of the alleged actual U-shaped relationship between the GDP growth rate and the hazard of exit.

TABLE V - FINDINGS OF PREVIOUS STUDIES ON THE RELATIONSHIP BETWEEN THE GDP GROWTH RATE AND THE SMALL BUSINESSES' HAZARD OF EXIT

\begin{tabular}{|c|c|c|c|}
\hline & $\begin{array}{c}\text { NEGATIVE } \\
\text { RELATIONSHIP }\end{array}$ & $\begin{array}{c}\text { POSITIVE } \\
\text { RELATIONSHIP }\end{array}$ & NO RELATIONSHIP \\
\hline STUDIES & $\begin{array}{c}\text { Gimeno and Others (1997), } \\
\text { Ilmakunnas and Topi (1999), } \\
\text { Bunn and Redwood (2003), } \\
\text { Jensen and Others (2008), } \\
\text { Oh and Others (2009), } \\
\text { Geroski and Others (2010), } \\
\text { Holmes and Others } \\
\text { (2010)**, Klapper and } \\
\text { Richmond (2011), Carreira } \\
\text { and Teixeira (2011), Christie } \\
\text { and Sjoquist (2012) and Falk } \\
\text { (2012). }\end{array}$ & Farinha (2005). & $\begin{array}{l}\text { Boeri and Bellmann } \\
(1995)^{*} .\end{array}$ \\
\hline COUNT & 11 & 1 & 1 \\
\hline
\end{tabular}

Obs.: 1) *These authors report results for the unemployment growth rate, but inform that they tried also with the growth of GDP, but it did not alter the results as the two variables were negatively and almost perfectly correlated;2) **These authors worked with the initial regional unemployment rate.

Out of the studies that found a negative association between the GDP growth rate and the hazard of exit, only the ones by Gimeno and Others (1997) and Falk (2012) are without extra evidence, since they did not fit either the industry growth rate or the industry entry rate besides the GDP growth rate.

Ilmakunnas and Topi (1999) reported a table of regressions for number of exits, instead of the exit rate, but apparently they did not come across with different results. They fitted the GDP growth rate and the number entering firms contemporaneously and found both monotonically associated to the number of exiting firms. As these variables are negatively and positively signed, they may be capturing, as predicted by the new proposed frame of reference, the downward and the upward trends of the actual U-shaped relationship between the GDP growth rate and the enterprises' exit rate. Also, within the predictions, the number of exits is probably troubling the GDP growth rate, which is as a result statistically significant only at the $10 \%$ level. If the specification included only the GDP growth rate, quadratically, without the number of entering firms, in accordance with the new proposed framework, most probably the GDP growth rate would come from the analyses highly significant, in both terms.

TABLE VI - EXTERNAL DETERMINANTS OF BUSINESS SURVIVAL

\begin{tabular}{|c|c|c|c|c|c|c|}
\hline \multirow{3}{*}{$\begin{array}{l}\text { Regressors/Independent } \\
\text { Variables }\end{array}$} & \multicolumn{6}{|c|}{ LINEAR REGRESSION MODEL } \\
\hline & \multicolumn{6}{|c|}{ Auxiliary Equations } \\
\hline & \multicolumn{2}{|c|}{$(1)$} & \multicolumn{2}{|c|}{$(2)$} & \multicolumn{2}{|c|}{ (3) } \\
\hline (GDP growth rate) (1) (1) (1) & -80.60 & $(3.05)^{*}$ & -82.57 & $(7.25)^{\star \star}$ & -142.75 & $(1.22)$ \\
\hline (GDP growth rate) (na) (2) (na) & n.a. & n.a. & 14.89 & $(4.31)^{\star}$ & n.a. & n.a. \\
\hline Number of entrants & n.a. & n.a. & n.a. & n.a. & 0.75 & $(0.55)$ \\
\hline Constant & $2,923.70$ & $(27.11)^{\star \star \star *}$ & $2,675.82$ & $(36.19)^{\star \star \star}$ & 530.56 & $(0.12)$ \\
\hline $\mathrm{R}^{2}$ adjusted & \multicolumn{2}{|c|}{0.62} & \multicolumn{2}{|c|}{0.93} & \multicolumn{2}{|c|}{0.54} \\
\hline $\mathrm{F}(1,4 / 2,3 / 2,3)$ & \multicolumn{2}{|c|}{$9.31^{*}$} & \multicolumn{2}{|c|}{$34.38^{* * *}$} & \multicolumn{2}{|c|}{3.99} \\
\hline
\end{tabular}

Obs: 1) Dependent variable: number of exiting firms; 2) First values in the main body of the table are coefficient estimates; 3) numbers in parentheses are absolute value t-statistics; 4$) *, * *$, and $* * *$ denote statistical significance at the $5 \%, 1 \%$, and $0.1 \%$ levels, respectively; 5) Number of observations: 6 . 
Ilmakunnas and Topi (1999) present extra evidence in the form of a bar graph showing entries and exits for 6 years from 1988 to 1993. Taking values from this graph and gdp growth rates for Finland from The World Bank, it was possible to build Table VI, which shows the fitting of three different specifications to capture in the linear regression model the influence of the GDP growth rate on the number of exits. So, equation (1) confirms the result obtained by the authors with the full sample. It is the monotonic negative relationship predicted by the reference study because the actual binomial U-shaped relationship is asymmetric, being that the relationship is stronger with respect the downtrend, as it is clued by the considerably higher z-statistics of the first term of the binomial specification of equation (2). Equation (3) shows that, according the new proposed framework predictions, the monotonic fitting of the GDP growth rate and the rate of entry in the same equation, may result in both variables being statistically insignificant, because the are highly correlated to each other.

Bunn and Redwood (2003) present extra evidence in the form of a graph plotting, on the one hand, the failure rate for their sample and the corporate liquidations rate against, on the other hand, the GDP growth for a sequence of 11 years. Taking the values from this graph, it was possible to build Table VII, which shows in Panel 1 the fitting of three different specifications to capture in the linear regression model the influence of the GDP growth rate on the enterprises' probability of exit. So, equation (1) confirms the result obtained by the authors with the full sample. It is the monotonic negative relationship predicted by the reference study because the actual binomial U-shaped relationship is asymmetric, being that the relationship is stronger with respect the downtrend, as it is clued by the considerably higher z-statistics of the first term of the binomial specifications of the equations (2) and (3). These same two equations show that the binomial specifications are better fittings, taking as base of comparison the R2 adjusted and the statistic $\mathrm{F}$ (in the case $\mathrm{F}$, for the quadratic specification only).

TABLE VII - EXTERNAL DETERMINANTS OF BUSINESS SURVIVAL PANEL 1 - SAMPLE FIRMS WITH 100 EMPLOYEES OR MORE

\begin{tabular}{|c|c|c|c|c|c|c|}
\hline \multirow{3}{*}{$\begin{array}{c}\text { Regressors/Independent } \\
\text { Variables }\end{array}$} & \multicolumn{6}{|c|}{ LINEAR REGRESSION MODEL } \\
\hline & \multicolumn{6}{|c|}{ Auxiliary Equations } \\
\hline & \multicolumn{2}{|c|}{ (1) } & \multicolumn{2}{|c|}{$(2)$} & \multicolumn{2}{|c|}{ (3) } \\
\hline (GDP growth rate)(1) (1) (2) & -0.59 & $(4.92)^{* *}$ & -1.28 & $(5.06)^{* \star}$ & -0.80 & $(4.79)^{* *}$ \\
\hline (GDP growth rate) $^{(\text {na) (2) (3) }}$ & n.a. & n.a. & 0.19 & $(2.90)^{*}$ & 0.17 & $(4.12)^{\star \star}$ \\
\hline Constant & 3.43 & $(10.15)^{\star \star \star}$ & 3.65 & $(13.96)^{* \star *}$ & 3.89 & $(11.20)^{\star \star *}$ \\
\hline $\mathrm{R}^{2}$ adjusted & \multicolumn{2}{|c|}{0.70} & \multicolumn{2}{|c|}{0.83} & \multicolumn{2}{|c|}{0.78} \\
\hline$F(1,9 / 2,8 / 2,8)$ & \multicolumn{2}{|c|}{$24.19^{\star * *}$} & \multicolumn{2}{|c|}{$26.26^{* * *}$} & \multicolumn{2}{|c|}{$18.54^{\star \star}$} \\
\hline
\end{tabular}

PANEL 2 - CORPORATE LIQUIDATIONS RATE

\begin{tabular}{|c|c|c|c|c|c|c|}
\hline \multirow{3}{*}{$\begin{array}{c}\text { Regressors/Independent } \\
\text { Variables }\end{array}$} & \multicolumn{6}{|c|}{ LINEAR REGRESSION MODEL } \\
\hline & \multicolumn{6}{|c|}{ Auxiliary Equations } \\
\hline & \multicolumn{2}{|c|}{ (1) } & \multicolumn{2}{|c|}{$(2)$} & \multicolumn{2}{|c|}{ (3) } \\
\hline (GDP growth rate)(1)(1) (2) & -0.26 & $(1.76)$ & -0.62 & $(1.43)$ & -0.51 & $(2.30)^{*}$ \\
\hline (GDP growth rate)(na) (2) (3) $^{(3)}$ & n.a. & n.a. & 0.10 & $(0.87)$ & 0.12 & $(2.10)$ \\
\hline Constant & 2.33 & $(5.51)^{* * *}$ & 2.44 & $(5.45)^{* * *}$ & 2.75 & $(5.95)^{\star \star \star}$ \\
\hline $\mathrm{R}^{2}$ adjusted & \multicolumn{2}{|c|}{0.17} & \multicolumn{2}{|c|}{0.15} & \multicolumn{2}{|c|}{0.31} \\
\hline$F(1,9 / 2,8 / 2,8)$ & \multicolumn{2}{|c|}{3.09} & \multicolumn{2}{|c|}{1.89} & \multicolumn{2}{|c|}{3.26} \\
\hline
\end{tabular}

Obs: 1) First values in the main body of the table are coefficient estimates; 2) numbers in parentheses are absolute value t-statistics; 3) *, **, and *** denote statistical significance at the 5\%, 1\%, and $0.1 \%$ levels, respectively; 4) Number of observations: 11 . 
Panel 2 exhibits results of the same experiment for the corporate liquidations rate. They are very different from the previous ones. Practically no fitting is statistically significant. This confirms results reported by other authors that large enterprises are much less subject to the impact of environmental macroeconomic conditions than their small counterparts are.

Jensen and Others (2008) worked also with the entry rate and reported a table of duration analysis in which this variable is highly statistically positively related to the hazard of exit in all specifications for new firms. However, for incumbent firms it is statistically insignificant in two specifications. This is evidence against the conclusions of the reference study, once it predicts that the entry rate is associated with the GDP growth rate in a U-shaped fashion and, as a consequence, its fitting together with the monotonic fitting of the GDP growth rate will result in statistically significant parameter estimates also because it will capture most probably the upward trend of the real U-shaped relationship between the GDP growth rate with the small firms' hazard of exit. However, with the introduction in a third specification of a new variable measured at the level of the industry, the entry rate becomes statistically significant at the 5\% level in a positive association with the hazard of exit also for incumbents. This restores support to the proposed new framework.

Oh and Others (2009)'s results are a striking proof that the proposed new framework is "correct". These authors specified the sectorial growth in addition to the GDP growth rate, and the sectorial growth came out of the analysis with a positive sign. It is highly probable that the sectorial growth is substituting for the other absent term of the "correct" binomial specification for the GDP growth rate. The fact that the z-statistic for the GDP growth rate is much higher than that for the sectorial growth might also be signaling this.

It is important to inform that it was not possible with data from the reference study to produce a specification that resulted in similar results as those of Oh and Others (2009)'s study. This is most probably due to the fact that in the reference study the manufacturing sector sales growth rate is associated with the hazard of exit in a perfect symmetric U-shaped fashion, what always result in lack of statistical significance in all attempts to fit it linearly.

In Geroski and Others (2010)'s work the industry entry rate might be playing the role of the second term of the actual U-shaped relationship between the GDP growth rate and the hazard of exit, once it is viewed, according to interpretations of the reference study, as an absolute value version of the GDP growth rate. Also, even more extra evidence is available in this case, as the authors reported a table of bivariate correlation. First, there is a coefficient of positive correlation between the GDP growth rate and the industry entry rate, but it is not very sizeable. It should be near zero, to best conforms itself to the prediction of the new proposed framework that the corresponding relationship is U-shaped, but, as it is not very sizeable, it even so corroborates the prediction that the industry entry rate is playing the role of the upward trend of the U-shaped relationship between the GDP growth rate and the hazard of exit. Necessity entrepreneurs' businesses are more informal than those of opportunity entrepreneurs, and this might be driving the small positive correlation coefficient. Second, the bivariate coefficient of correlation between the GDP growth rate and the exit rate is nil, what further proves that the actual relationship is Ushaped, and that the fitting of a linear specification might result in lack of statistical significance if the U-shaped relationship is perfectly or almost perfectly symmetric and neither the industry growth rate nor the industry entry rate is fitted contemporaneously.

Holmes and Others (2010) in truth dealt with the unemployment rate, instead of the GDP growth rate. However, their study is included in the analyses in the hope that these variables are highly correlated, as is the case in Boeri and Bellmann (1995)'s work. Holmes and Others (2010) dealt also with the initial sectorial growth rate. For the micro-enterprise subset, the regional 
unemployment rate was found to be monotonically, negatively associated to the survival probability at the conventional level of statistical significance, whereas the sectorial growth rate positively only at the $15 \%$ level. If the signs were the same, then the result would be strong evidence in favor of the new proposed framework, because in such a case one variable would be capturing the downtrend of the real U-shaped relationship between the GDP growth rate and the hazard of exit and the other one the uptrend. However, the choice of groupings might be driving the results, since, against common practice, the small firms were grouped together with mediumsized and large enterprises instead of together with the micro-enterprises. In the SMEs subset, which includes enterprises with up to 500 employees, both variables were found to be highly statistically insignificant. This might mean either that it is the result of trying a linear fitting when the relationships are almost or perfectly symmetrically non-linear, what would be evidence in favor of new proposed framework, or that the larger enterprises are not so much subject to sectorial and macroeconomic conditions.

Klapper and Richmond (2011), like Bunn and Redwood (2003), report a graph, only that in their case the sequence is for 19 years, covering the GDP growth rate, the exit rate and the entry rate. However, results with the use of data extracted from the graph are frustrating, since no parameter estimate is statistically significant. There seems to be a problem with their data, in view of the fact that the coefficient of bivariate correlation between their entry rate and the exit rate is negative and very high, that is, $r=-0.66$, and this does not change much by lagging. This blatantly contradicts Geroski (1995)'s famous statement that "the most palpable consequence of entry is exit". The impression is that the number of entrants is added to the number of incumbents to calculate the exit rate, so artificially lowering it and causing the high negative correlation. Moreover, the authors do not use the exit rate in the Cox regression analyses, a procedure that runs against common practice and hints that there should be a problem with the variable.

Carreira and Teixeira (2011) produce a much more complicated case that does not adjust itself to the predictions of the new proposed framework, as they reported finding the expected negative relationships between, on the one side, the GDP growth rate and the industry growth rate, respectively current and time-varying defined, and on the other side, the hazard of exit at satisfactory levels of statistical significance, but also that the industry entry rate, also time-varying defined, had no statistical significance. The reference study predicts the findings of the statistically significant linear relationships of the hazard rate with the GDP growth rate and the industry growth rate in case of real asymmetric U-shaped relationships. The problem is with the industry entry rate that should have captured according those predictions the effects of the positive uptrend of the U-shaped relationships with the GDP growth rate and the industry growth rate. The only satisfactory explanation concerns the study's sampling strategy, which included all enterprises with more than a hundred employees, considered only a sample of the ones with less than a hundred and more than twenty employees and none of the ones with less than 20 employees. Mata and Others (1995) and Oh and Others (2009) showed that the relationships between, on the one hand, the hazard of exit and, on the other hand, the GDP growth rate, the industry growth rate and the industry entry rate hold only for the classes of small- and medium-sized enterprises and for the totality of the enterprises because it includes those two classes. But, in the work under revision, the far higher representativeness of the two smaller classes of enterprises seems not to have been preserved in view of its sampling strategy, which might be driving the unexpected result.

Christie and Sjoquist (2012)'s study falls also into the case of studies that have found a negative association between the GDP growth rate and the hazard of exit at the same time that have found a positive association between the industry entry rate and the hazard of exit. Thus, the industry entry rate might be playing the role of the second term of the actual U-shaped relationship between the GDP growth rate and the hazard of exit. This is evidence in favor of the new proposed framework. 
Going over to the third column of Table V, Farinha (2005)'s is the only study that diverges from the predicted most probable result of a negative monotonic relationship between the GDP growth rate and the small manufacturing enterprises' hazard of exit. But even so it lends strong support to the present work in view of the fact that she reports mostly counterintuitive, unexpected results for the variable GDP growth rate. Her tables of Cox regression equations show that both current and initial GDP growth rates are associated at high levels of statistical significance with the new firms' hazard of exit. Moreover, the author informs that when the variable GDP growth is included with a 3 year lag, the sign of the estimated coefficient is the opposite and significant.

First, the informed, but not reported, result coincides with findings reported in Section 3, that is, that the three-year-lagged GDP growth rate is a robust determinant of the firms' probability of survival, exerting a positive influence. Second, the result that the current GDP growth rate is monotonically, positively related with the hazard of exit is in accordance with predictions of the reference study. Such a result might come out from an attempt to fit a linear specification when the actual relationship is in fact a U-shaped one. Such interpretation is consistent with the possibility that in the work under review the U-shaped relationship is asymmetric, being that the uptrend is either more numerous in terms of residuals, or more clearly defined as a tendency, with the residuals clustered more closely around a virtual fitting curve, or more inclined, or even all together. The source of such asymmetry might be because either Farinha (2005) worked with only new firms, as opposed to incumbent, or, dealt with a time span that includes only one economic cycle, as stated by the author, or both. Last, there is the finding that the initial GDP growth rate is monotonically, positively associated to the new firms' failure probability. This too can be taken as evidence in favor of the reference study in view of the fact that it seems reasonable to think that the initial GDP growth rate should be related in a U-shaped fashion too with the small firms' hazard of exit. The number of bad new firms with short life prospects should be higher in both recessions and booms than in times of economic stability and this would generate the U-shaped relationship between the initial GDP growth rate and the hazard of exit. Last, only in one specification the current and the initial GDP growth rates enter together the Cox regression equation in Farinha (2005)'s study, and none plays the role of the downtrend in the U-shaped relationship, most probably because there is not a correlation coefficient of the right size between them to produce such a result.

TABLE VIII - EXTERNAL DETERMINANTS OF SMALL BUSINESS SURVIVAL

\begin{tabular}{|c|c|c|c|c|c|c|}
\hline \multirow{3}{*}{$\begin{array}{c}\text { Regressors/Independent } \\
\text { Variables }\end{array}$} & \multicolumn{6}{|c|}{ COX PROPORTIONAL HAZARD MODEL } \\
\hline & \multicolumn{6}{|c|}{ Auxiliary Equations } \\
\hline & \multicolumn{2}{|c|}{ (1) } & \multicolumn{2}{|c|}{$(2)$} & \multicolumn{2}{|c|}{ (3) } \\
\hline 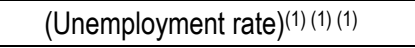 & -0.48 & $(2.68)^{* *}$ & -19.38 & $(5.92)^{* * *}$ & -0.48 & $(2.66)^{* *}$ \\
\hline (Unemployment rate) $)^{(\text {na) (2) (na) }}$ & n.a. & n.a. & 0.90 & $(5.91)^{\star * *}$ & n.a. & n.a. \\
\hline $\begin{array}{l}\text { (Manufacturing sector sales growth } \\
\text { rate }+30)^{++}\end{array}$ & n.a. & n.a. & n.a. & n.a. & $-0.16 e-2$ & $(0.16)$ \\
\hline $\mathrm{R}_{\mathrm{p}}^{2}$ & \multicolumn{2}{|c|}{0.13} & \multicolumn{2}{|c|}{0.61} & \multicolumn{2}{|c|}{0.13} \\
\hline LR chi2(1/2/2) & \multicolumn{2}{|c|}{$8.17^{\star \star}$} & \multicolumn{2}{|c|}{$57.79^{\star \star *}$} & \multicolumn{2}{|c|}{$8.19^{*}$} \\
\hline
\end{tabular}

Obs: 1) First values in the main body of the table are coefficient estimates; 2) numbers in parentheses are absolute value $\mathrm{z}$-statistics; 3$) *, * *$, and $* * *$ denote statistical significance at the $5 \%, 1 \%$, and $0.1 \%$ levels, respectively; 4) ++ Adding 30 was necessary in order to make it possible to extract the square root for the originally negative values; 5 ) Number of events/observations (firms): 46/61.

Going over to the fourth column of Table V, Boeri and Bellmann (1995)'s is the only piece of research to come across with lack of statistical significance for the GDP growth rate. The first problem with Boeri and Bellmann (1995)'s duration analyses is that they are either underfitted or overfitted. The proposed new framework predicts that the macroeconomic, the industry and the 
entry variables are all related to one another, so that, if they are specified together in the same equation, they will most probably trouble each other. For each manufacturing sector of Boeri and Bellmann (1995)'s work, there are the fitting of two equations. In the first equation there is only one variable, the unemployment growth rate, to represent the real U-shaped relationship, when two are needed. In the second equation there are three, the unemployment growth rate, the industry growth rate and the industry entry rate, when only two are needed. So, in the seven manufacturing sectors, none of the estimated parameters for the unemployment growth rate in the first equations is statistically significant, with only two marginally approaching statistical significance. This is what exactly happens in the reference study when the GDP growth rate and the industry growth rate are specified monotonically, as reported in Table I, equations (1) and (4). On the other hand, in the seven manufacturing sectors none of the estimated parameters for either the unemployment growth rate or the industry entry rate in the second equations is statistically significant, with only some marginally approaching statistical significance. They are probably troubling one another because they are competing for capturing the second trend of the U-shaped relationship, once the first is already being captured by the industry growth rate that is statistically significant in three of the second equations.

Boeri and Bellmann (1995), from their results in their Table 1, concluded that there was no relationship between the unemployment grow rate and the firms' hazard of exit, in view of lack of statistical significance. This result is already enough proof in favor of the new proposed frame of reference, since it can well be one of the three possible outcomes predicted by the reference study when trying to fit a linear specification to an actual U-shaped relationship. Besides, it is the result for large firms, obtained in some studies that broke down the analysis by size, and the sectors for which the authors presented results are not the ones where small firms are most prevalent. Moreover, if the conventional statistical significance benchmarks are relaxed, four specifications might be seen as marginally significant. Out of them, one is positively signed (z-statistic being 1.47), which is in line with expectations and intuition. The three others are negatively signed (zstatistics being $-1.48,-1.52$ and -1.62 ), which is totally against expectations and intuition, meaning that higher unemployment growth rates lower the enterprises' failure probability. As Table VIII, auxiliary equation (1) shows, this is the very same result for the reference study. However, nothing of this is true, since the linear fitting is artificial and the real relationship is U-shaped, as demonstrated by the results of auxiliary equation (2). In two of these four cases of Boeri and Bellmann (1995)' work, the specification includes the measure of the industry growth rate, whose signs are consistent with the possibility that the unemployment rate and the industry growth rate are capturing the downtrend and the uptrend of the GDP growth rate U-shaped relationship with the hazard of exit. Also, these two "successful" cases are in the mechanical engineering and tools manufacturing sectors where the small firms are more or less prevalent. Auxiliary equation (3) in Table VIII shows this last mentioned result does not happen in the reference study, probably because, the U-shaped relationship of the manufacturing sector sales growth rate with the hazard of exit is perfectly symmetric, resulting in lack of statistical significance always that a linear fitting is tried.

Harris and Li (2010) did not deal with the GDP growth rate, but even so present extra evidence on it, since they reported a graph plotting in sequence of seven years the exit rate for their total sample and for groups of enterprises broken down by size. This allowed the building of table IX. The annual UK GDP growth rate was taken from the World Bank. Conventional benchmarks should be relaxed, since the sample size is very small. Notwithstanding, the pattern for the full sample is in accordance with the new proposed framework, whereas that for the larger enterprises is much more poorly defined, in line with those of other studies. 
TABLE IX - EXTERNAL DETERMINANTS OF BUSINESS SURVIVAL

PANEL 1 - FULL SAMPLE FIRMS

\begin{tabular}{|c|c|c|c|c|c|c|}
\hline \multirow{3}{*}{$\begin{array}{l}\text { Regressors/Independent } \\
\text { Variables }\end{array}$} & \multicolumn{6}{|c|}{ LINEAR REGRESSION MODEL } \\
\hline & \multicolumn{6}{|c|}{ Auxiliary Equations } \\
\hline & \multicolumn{2}{|c|}{ (1) } & \multicolumn{2}{|c|}{$(2)$} & \multicolumn{2}{|c|}{ (3) } \\
\hline$(\text { GDP growth rate) })^{(1)(1)(1 / 2)}$ & 0.03 & (2.42) & -0.20 & (1.42) & -1.58 & (1.47) \\
\hline$(\text { GDP growth rate) })^{(\text {na) (2) (1) }}$ & n.a. & n.a. & 0.03 & (1.64) & 0.46 & $(1.56)$ \\
\hline Constant & 0.16 & $(3.87)^{\star}$ & 0.52 & (2.30) & 1.57 & $(1.62)$ \\
\hline$R^{2}$ adjusted & \multicolumn{2}{|c|}{0.45} & \multicolumn{2}{|c|}{0.59} & \multicolumn{2}{|c|}{0.55} \\
\hline$F(1,5 / 2,4 / 2,4)$ & \multicolumn{2}{|c|}{5.88} & \multicolumn{2}{|c|}{5.27} & \multicolumn{2}{|c|}{4.69} \\
\hline
\end{tabular}

PANEL 2 - FIRMS WITH 200 OR MORE EMPLOYEES

\begin{tabular}{|c|c|c|c|c|c|c|}
\hline \multirow{3}{*}{$\begin{array}{c}\text { Regressors/Independent } \\
\text { Variables }\end{array}$} & \multicolumn{6}{|c|}{ LINEAR REGRESSION MODEL } \\
\hline & \multicolumn{6}{|c|}{ Auxiliary Equations } \\
\hline & \multicolumn{2}{|c|}{$(1)$} & \multicolumn{2}{|c|}{$(2)$} & \multicolumn{2}{|c|}{ (3) } \\
\hline (GDP growth rate)(1) (1) (1/2) & 0.04 & $(2.09)$ & -0.06 & $(0.19)$ & -0.64 & $(0.29)$ \\
\hline (GDP growth rate) (na) (2) (1) & n.a. & n.a. & 0.01 & $(0.34)$ & 0.22 & $(0.36)$ \\
\hline Constant & $-0.36 e-2$ & $(0.05)$ & 0.16 & $(0.33)$ & 0.57 & $(0.29)$ \\
\hline $\mathrm{R}^{2}$ adjusted & \multicolumn{2}{|c|}{0.36} & \multicolumn{2}{|c|}{0.22} & \multicolumn{2}{|c|}{0.21} \\
\hline$F(1,5 / 2,4 / 2,4)$ & \multicolumn{2}{|c|}{4.38} & \multicolumn{2}{|c|}{1.86} & \multicolumn{2}{|c|}{1.83} \\
\hline
\end{tabular}

Obs: 1) First values in the main body of the table are coefficient estimates; 2) numbers in parentheses are absolute value $\mathrm{t}$-statistics; 3$) * * *$, and $* * *$ denote statistical significance at the $5 \%, 1 \%$, and $0.1 \%$ levels, respectively; 4) Number of observations: 7 .

\subsection{THE INDUSTRY GROWTH RATE}

One prediction of the new postulated framework is that the negative association between the industry growth rate and the hazard of exit is the most common outcome to be obtained by studies fitting a monotonic specification. Table $\mathrm{X}$ exhibits previous results from the small businesses' empirical literature according to the nature of the finding. The counting is nine for the decreasing relationship, six for the increasing and seven for no relationship. The first prediction holds, but it is evidence in favor of the prevalent conventional frame of reference too. So, the analysis will proceed to check for extra evidence in the studies that have found a negative relationship of the industry growth rate with the hazard of exit.

TABLE X - FINDINGS OF PREVIOUS STUDIES ON THE RELATIONSHIP BETWEEN THE INDUSTRY GROWTH RATE AND THE SMALL BUSINESSES'S HAZARD OF EXIT

\begin{tabular}{|c|c|c|c|}
\hline & $\begin{array}{c}\text { NEGATIVE } \\
\text { RELATIONSHIP }\end{array}$ & $\begin{array}{c}\text { POSITIVE } \\
\text { RELATIONSHIP }\end{array}$ & NO RELATIONSHIP \\
\hline & $\begin{array}{c}\text { Boeri and Bellmann (1995), } \\
\text { Audretsch (1995), Mata and } \\
\text { Others (1995), Strotmann } \\
\text { STUDIES }\end{array}$ & $\begin{array}{c}\text { Boeri and Bellmann } \\
\text { (1995), Everett and } \\
\text { Watson (1998), Oh and } \\
\text { Others (2009), Shiferaw } \\
\text { (2009), Holmes and Others and Li } \\
\text { (2010), Carreira and } \\
\text { Teixeira (2011), Feizpour } \\
\text { and Others (2014), Varum } \\
\text { and Others (2014) and } \\
\text { Resende and Others (2016) }\end{array}$ & $\begin{array}{c}\text { Mond and Helmers and } \\
\text { (1995), Fotopoulos and } \\
\text { Louri (2000a), Disney } \\
\text { and Others (2003) (at } \\
\text { first), Audretsch and } \\
\text { Others (2004) (at final), } \\
\text { Christie and Sjoquist } \\
\text { (2012), and Fernandes } \\
\text { and Paunov (2015) }\end{array}$ \\
\hline COUNT & 9 & 6 & 7 \\
\hline
\end{tabular}


Out of these studies only the one by Audretsch (1995) is without extra evidence, since it did not fit the industry entry rate besides the industry growth rate.

To adhere strictly to the predictions of the new proposed framework, all studies that have found a negative association between the industry growth rate and the hazard of exit at the same that have found a positive association between the industry entry rate and the hazard rate carry with them extra evidence of the alleged actual U-shaped relationship between the industry entry rate and the hazard of exit. This is the case of Strotmann (2007), Feizpour and Others (2014), Varum and Others (2014) and Resende and Others (2016). The reference study predicts that the industry entry rate is associated in a U-shaped relationship with the industry growth rate. As the industry growth rate is associated in a U-shaped fashion with the hazard of exit, the monotonic direct association between the industry entry rate and the hazard rate is equivalent to a direct association between the absolute values of the industry growth rates and the hazard of exit. In other words, the direct association between the industry entry rate and the hazard of exit is econometrically the same thing and is substituting for the upward trend of the U-shaped relationship between the industry growth rate and the hazard of exit.

In Boeri and Bellmann (1995)'s Table 1, under the heading Tools, their industry growth measure reaches high statistical significance in a negative relationship with the hazard of exit. Additionally to this finding, there is extra evidence in support of the predictions of the new proposed framework, once the authors fitted also the industry entry rate and the unemployment rate. Both are signed in line with the prediction that they are competing for capturing the uptrend of the actual U-shaped relationship between, on the one hand, either the GDP growth rate or the industry growth rate and, on the other hand, the manufacturing enterprises' hazard of exit. As their z-statistics are not extremely low, taking one of the two variables out of the equation will most probably make the other one statistically significant.

Mata and Others (1995) would be another example of the cases of Strotmann (2007), Feizpour and Others (2014), Varum and Others (2014) and Resende and Others (2016) mentioned above. However, the authors fitted a third variable, that is, the multiplicative interaction between the industry growth rate and the industry entry rate, which reached high statistical significance in a monotonic positive association with the small firms' probability of exit.

The best explanation, according to the new proposed framework is that, as the relationships are stochastic and the quadratic is rarely the best binomial fitting, residuals are left along all the way and around the U-shaped relationship, being that these residuals are then capturable by the fitting of another close version of either the industry growth rate or the industry entry rate. The sizes of the absolute values of the z-statistics for the three variables, that is, 4.00 for the entry rate, 3.60 for the industry growth rate and 3.47 for the interaction are consistent with this interpretation. The interaction has the lowest, being this consistent with the argument that it is capturing residuals from a poorly fitted specification.

Table XI exhibits results from an experiment with data from the reference study that show that this might really be the case for the study under review. Auxiliary equation (1) is a better fitting by comparison with auxiliary equation (3), since it has higher LR chi2 and $R_{p}^{2}$ and since a GDP growth rate of size $3.64 \%$ is a better fitting than $4.59 \%$ for the point in the scale of the GDP growth rate where the minimum of the function of the hazard rate takes place, as an inspection of Graph 01 makes that possible of being seen. Now, as auxiliary equation (1) is a better fitting, it does not leave many residuals or, at least, not sizeable ones, so that the fitting of an extra version of the GDP growth rate does not reach statistical significance. This is shown in auxiliary equation 
(2). On the other hand, auxiliary equation (4) shows that auxiliary equation (3), which is a poor fitting, left residuals, captured by the interaction, which this time reaches statistical significance.

The above interpretation becomes even more plausible, when it is reminded that the GDP growth rate is absent from Mata and Others (1995)'s equation, has a much more powerful explaining power and is associated with the hazard of exit in a U-shaped fashion too. Thus, such absence leaves much variance in the small firms' failure probability unexplained.

TABLE XI - EXTERNAL DETERMINANTS OF SMALL BUSINESS SURVIVAL

\begin{tabular}{|c|c|c|c|c|c|c|c|c|c|c|}
\hline \multirow{3}{*}{$\begin{array}{c}\text { Regressors/Independent } \\
\text { Variables }\end{array}$} & \multicolumn{8}{|c|}{ COX PROPORTIONAL HAZARD MODEL } & \multirow{2}{*}{\multicolumn{2}{|c|}{ PEARSON CORRELATION }} \\
\hline & \multicolumn{8}{|c|}{ Auxiliary Equations } & & \\
\hline & \multicolumn{2}{|r|}{ (1) } & \multicolumn{2}{|r|}{ (2) } & \multicolumn{2}{|r|}{ (3) } & \multicolumn{2}{|r|}{ (4) } & $\begin{array}{l}\text { GDP } \\
\text { growth } \\
\text { rate }\end{array}$ & $\begin{array}{c}\text { manufacturing } \\
\text { sector } \\
\text { performance }\end{array}$ \\
\hline $\begin{array}{l}\text { GDP growth rate } X \\
\text { Manufacturing sector } \\
\text { performance }\end{array}$ & n.a. & n.a. & 0.01 & $(1.43)$ & n.a. & n.a. & 0.03 & $(2.99)^{\star *}$ & $-0.49^{* * *}$ & $0.61^{* * *}$ \\
\hline GDP growth rate $e^{(1)(1)(3)(3)}$ & -2.24 & $(6.24)^{\star * \star}$ & -2.06 & $(5.40)^{\star * *}$ & -0.28 & $(5.80)^{\star \star \star}$ & -0.19 & $(4.28)^{\star * *}$ & & \\
\hline GDP growth rate r(2)(2)(4)(4) $^{2}$ & 0.31 & $(5.60)^{\star * \star}$ & 0.29 & $(5.27)^{\star \star \star}$ & 0.13 & $(5.71)^{\star \star \star}$ & 0.03 & $(4.38)^{\star \star \star}$ & & \\
\hline $\begin{array}{l}\text { Manufacturing sector } \\
\text { performance }\end{array}$ & -0.13 & $(4.99)^{\star \star \star *}$ & -0.17 & $(4.34)^{\star \star *}$ & -0.14 & $(5.56)^{\star \star \star}$ & -0.20 & $(5.36)^{\star \star \star}$ & & \\
\hline $\begin{array}{l}\text { 3-year-lagged GDP growth } \\
\text { rate }\end{array}$ & -0.60 & $(4.88)^{\star \star \star}$ & -0.62 & $(4.83)^{\star \star \star}$ & -0.64 & $(5.16)^{\star * \star}$ & -0.73 & $(5.09)^{\star \star \star}$ & & \\
\hline 1998 year dummy & 5.53 & $(5.80)^{* * *}$ & 5.46 & $(5.73)^{\star \star \star *}$ & 5.88 & $(5.75)^{\star * \star}$ & 5.80 & $(5.47)^{\star * *}$ & & \\
\hline $\mathrm{R}_{\mathrm{p}}^{2}$ & \multicolumn{2}{|r|}{0.78} & \multicolumn{2}{|c|}{0.79} & \multicolumn{2}{|r|}{0.75} & \multicolumn{2}{|c|}{0.76} & & \\
\hline LR chi2(5/6/5/6) & \multicolumn{2}{|c|}{$92.66^{\star \star *}$} & \multicolumn{2}{|c|}{$94.79^{* * *}$} & \multicolumn{2}{|c|}{$84.95^{\star \star *}$} & \multicolumn{2}{|c|}{$85.08^{\star \star \star}$} & & \\
\hline
\end{tabular}

Obs: 1) First values in the main body of the table are coefficient estimates; 2) numbers in parentheses are absolute value $\mathrm{Z}$-statistics; 3) *, **, and *** denote statistical significance at the 5\%, 1\%, and $0.1 \%$ levels, respectively; 4) Number of events/observations (firms): 46/61.

Holmes and Others (2010) dealt with the initial sectorial growth rate and with the initial unemployment rate. As seen in Subsection 4.1, these variables did not work in a way so as to produce extra evidence in favor of the new proposed framework.

The extra evidence in Carreira and Teixeira (2011)'s research, additional to the finding that the industry growth rate is negatively related to the enterprises' failure likelihood, is against the new proposed framework. As this case has been addressed in Subsection 4.1, suffice note here that flaws in the sampling design of this work might be driving its contradictory results.

Proceeding to the studies that have found a positive impact of the industry growth rate on the hazard of exit, it must be said that for them to be considered evidence in favor of the new frame of reference there should be elements of proof that the happening of their finding might be due to the reasons upon which the predictions are built. In the reviews coming next, this is what will be searched for.

Boeri and Bellmann (1995)'s industry growth duration analysis equations are overfitted as seen in the Subsection 4.1. In these authors' Table 1, under the mechanical engineering heading, the finding of a positive and statistically significant relationship between their industry growth rate measure, that is, the manufacturing sector sales growth rate, and the hazard of exit might be attributable to the possibility that the industry growth rate is capturing the upward trend of its real U-shaped relationship or of that of the GDP growth rate. The unemployment growth rate, which the authors inform, is inversely and almost perfectly correlated with the GDP growth rate, most 
probably, would, if the industry entry rate were taken out of the equation, reach statistical significance in a positive association with the hazard, so capturing the downward trend. Under the heading of manufacturing total, the positive association is consistent with the prediction that the industry growth rate measure is capturing the upward trend. However, the sign of the industry entry rate should be negative, since the unemployment rate is totally statistically insignificant. As the proposed new framework cannot explain this, there must be a problem with the sampling procedure or with the data. One thing is sure, Boeri and Bellmann (1995) presented results for manufacturing sectors in which the small manufacturing firms are not the most prevalent, and research that has broken down results by size of the enterprises has reached the conclusion that the larger enterprises' hazard of exit is not so much subject to macroeconomic and sectorial conditions.

Everett and Watson (1998)'s finding of a positive relationship leaves no doubt that it is the result of a misguided attempt to fit a linear specification when in fact the actual relationship is asymmetrically U-shaped. The authors reported in their Table VI, column discontinuance of business, also the fitting of a six-month-lagged version of their proxy for the industry growth rate, namely, retail sales, which proved to be associated negatively with the hazard of exit. As it seems reasonable to assume that the lagged and the current measures are highly correlated to each other, that there is a higher correlation between the current version and the hazard rate and that the author's Table VI shows a much tight adjustment by the current retail sales, as indicated by its much higher statistical significance level as compared to that of the lagged retail sales, it may be concluded that what the authors in fact did was to fit a version of the two terms of a binomial specification, let us say, a quadratic one, being that current retail sales adjusted itself to the upward trend and the lagged to the downward trend. The real U-shaped relationship is asymmetric, being that the uptrend is either more numerous in terms of residuals, or more clearly defined as a tendency, with the residuals clustered more closely around a virtual fitting curve, or more inclined, or even all these together. The authors' added information that individually current retail sales and lagged retail sales are both positively related to failure reinforces conclusions.

Oh and Others (2009)'s table of Cox regressions shows not only that their measure of industry growth rate is monotonically directly associated with the hazard of exit but also that the GDP growth rate is negatively monotonically related to the hazard of exit. This is evidence in favor of the reference study theses. The reference study predictions that both are associated with the hazard of exit according to a U-shaped fashion mean then that, in Oh and Others (2009)'s SSEs equation, either sectorial growth is substituting for the other absent term of GDP growth or is the other way round. Apparently, it is the former case, since the t-statistic for the GDP growth is much higher than that for the monotonic relationship between sectorial growth and the hazard of exit.

It is important to inform that it was not possible with data from the reference study to produce a specification that resulted in similar findings to those of Oh and Others (2009). This is most probably due to the fact that in the reference study the manufacturing sector sales growth rate is associated with the hazard of exit in a perfect symmetric U-shaped fashion, what always results in lack of statistical significance in all attempts to fit it linearly.

Shiferaw (2009)'s unexpected results are strong support to the new proposed framework. This author reported finding highly statistically significant monotonic relationships between, on the one hand, the industry growth rate and the industry entry rate, both time varying, and, on the other hand, the hazard of exit. However, signs are exactly the reverse of expected, positive with the industry growth rate and negative with the industry entry rate. In face of interpretations and predictions of the reference study, the conclusion for Shiferaw (2009)'s results is that each variable is capturing in the Cox regressions one of the two different effects of the actual U-shaped 
relationship between either, on the one hand, the GDP growth rate, which is missing in his study, or the industry growth rate and, on the other hand, the hazard of exit. Most probably it is the real U-shaped relationship with the GDP growth rate, because, according with the reference study, it is by far much stronger than that of the industry growth rate. In this case, the industry entry rate, which is according to interpretations of the reference study, an absolute value version of either the GDP growth rate or the industry growth rate, is capturing the effects of the GDP growth rate in the downtrend and the industry growth rate is capturing the effects of the GDP growth rate in the uptrend of the real U-shaped relationship between the GDP growth rate and the hazard of exit. As the reference study states that the GDP growth rate is correlated with the industry growth rate, this piece of evidence lends support also to the relationship between the industry growth rate and the hazard of exit, which is the object of this subsection.

Harris and $\mathrm{Li}$ (2010)'s findings, reported in a table of Cox regressions, in which the variables industry growth rate and a version of industry entry rate are marginally statistically significant in monotonic specifications, and, against expectations and intuition, the directions of the fitted relationships are positive and negative respectively, provide the same evidence as Shiferaw (2009)'s. The only difference is that Harris and Li (2010) specified an interaction of the industry growth rate with age, which resulted in a statistically marginally significant association with the hazard of exit, at the expense of turning the industry growth rate statistically insignificant, although keeping the same positive sign. Thus, conclusions do not change and are the same as in Shiferaw (2009)'s case.

Helmers and Rogers (2010)'s findings are identical to those of Shiferaw (2009)'s. Thus, they are favorable evidence to the postulates of the new proposed framework.

Turning now to the studies that have come across with statistical insignificance of the industry growth rate, Mahmood (1992)'s work provides a strong piece of evidence since this author reported Cox regression results that showed that the industry growth rate coefficient, being statistically insignificant, varied in between positive and negative in an array of manufacturing sectors. This is the very outcome predicted from a misguided attempt to fit a linear specification when the actual U-shaped relationship is perfectly or almost perfectly symmetrical.

Boeri and Bellmann (1995)'s Table 1 shows that for the car industry, chemicals, plastics and electrical engineering the measure of industry growth rate is statistically insignificant. As the unemployment growth rate is also statistically insignificant, then the reason for the industry growth rate being statistically insignificant is probably that the real U-shaped relationship is perfectly asymmetric. So, according to the predictions of the reference study, the attempt to fit a linear specification will result in a statistically insignificant coefficient estimate. If both variables were statistically significant, they would, according to the predictions of the reference study, take equal signs, meaning they would be capturing the downward and upward trend of the U-shaped relationship with the hazard of exit.

Fotopoulos and Louri (2000a)'s finding is the same as Mahmood (1992)'s, that is lack of statistical significance of the industry growth rate. However, the former authors fitted also the industry entry rate, which proved to be statistically significantly positively associated to the hazard rate. However, the authors report in the text that the industry entry rate is not current or time varying, but only the initial one, that is, the one of the year of the birth of the new firm. Thus, failure to find a statistical significant association between the industry growth rate and the likelihood of exit is most probably due to the fact that the authors did not try the fitting of a binomial specification. The real U-shaped relationship is most probably symmetric and trying to fit a monotonic linear specification in this case will result in total lack adjustment, which explains lack of statistical significant of the estimated coefficient. The initial industry entry rate could not 
play the role of the one of the terms of a quadratic specification in this case because it is not correlated with the industry growth rate, a postulation of the study of reference. The final conclusion is that there is no reason to doubt that the Fotopoulos and Louri (2000a)'s finding is strong evidence that lends support to the reference study theses.

Disney and Others (2003)'s study is perhaps the one piece of evidence that lends the strongest support to the findings of the reference study. It brings in its Table 7 estimates of a Cox proportional hazard regression for new small manufacturing enterprises, during the period from 1974 to 1991. To deal with the possible influence of the cycle these authors specified real manufacturing output growth. They found at first that demand (real manufacturing output growth) had a poorly defined positive effect, but suggested that increases in demand raised the hazard rate. These authors then fitted an interaction with age and found that both the linear specification and the interaction were then highly statistically significant, associated with the hazard of exit positively and negatively respectively. The authors then stated that interaction with age showed that the perhaps counter-intuitive positive effect of real manufacturing output growth on the hazard was due to the failure to interact with age. So, an increase in demand appeared to raise hazard rates, but this was true however only for young firms, since after two years an increase in demand lowered hazard rates.

TABLE XI - EXTERNAL DETERMINANTS OF SMALL BUSINESS SURVIVAL

\begin{tabular}{|c|c|c|c|c|c|c|c|c|}
\hline \multirow[b]{3}{*}{$\begin{array}{l}\text { Regressors/Independent } \\
\text { Variables }\end{array}$} & \multicolumn{6}{|c|}{ COX PROPORTIONAL HAZARD MODEL } & \multirow{2}{*}{\multicolumn{2}{|c|}{ PEARSON CORRELATION }} \\
\hline & \multicolumn{6}{|c|}{ Auxiliary equations } & & \\
\hline & \multicolumn{2}{|c|}{$\begin{array}{c}\text { From } \\
\text { Table I Panel } 2 \\
\text { Equation } 5 \\
\text { (1) }\end{array}$} & \multicolumn{2}{|c|}{$\begin{array}{c}\text { From } \\
\text { Table I Panel } 2 \\
\text { Equation } 4 \\
(2)\end{array}$} & \multicolumn{2}{|c|}{ (3) } & $\begin{array}{l}\text { (Manufacturing } \\
\text { sector sales growth } \\
\text { rate }+30)^{++}\end{array}$ & $\begin{array}{l}\text { Year of } \\
\text { exit or of } \\
\text { censoring }\end{array}$ \\
\hline $\begin{array}{l}\text { (Manufacturing sector sales growth rate } \\
+30)^{++} X \text { Year of exit or of censoring }\end{array}$ & n.a. & n.a. & n.a. & n.a. & 0.09 & $(6.20)^{\star * *}$ & $0.55^{\star * *}$ & $0.78^{* * *}$ \\
\hline $\begin{array}{l}\text { (Manufacturing sector sales growth rate } \\
\qquad+30)^{(1)(1)(1))++}\end{array}$ & -0.11 & $(4.51)^{\star * *}$ & $-0.02 e-1$ & $(0.25)$ & -0.02 & $(7.29)^{\star \star \star}$ & & \\
\hline $\begin{array}{l}\text { (Manufacturing sector sales growth rate } \\
\qquad+30)(\text { (2) (na) (na) ) ++ }\end{array}$ & $0.01 \mathrm{e}-1$ & $(4.45)^{\star * *}$ & n.a. & n.a. & n.a. & n.a. & & \\
\hline$R_{p}^{2}$ & \multicolumn{2}{|c|}{0.25} & \multicolumn{2}{|c|}{0.00} & \multicolumn{2}{|c|}{0.82} & & \\
\hline LR chi2(2/2/2) & \multicolumn{2}{|c|}{$17.34^{* * *}$} & \multicolumn{2}{|c|}{0.06} & \multicolumn{2}{|c|}{$105.50^{* * *}$} & & \\
\hline
\end{tabular}

Obs: 1) First values in the main body of the table are coefficient estimates; 2) numbers in parentheses are absolute value $\mathrm{z}$-statistics; 3) *, **, and *** denote statistical significance at the 5\%, 1\%, and $0.1 \%$ levels, respectively; 4) ++ Adding 30 was necessary in order to make it possible to extract the square root for the originally negative values; 5 ) Number of events/observations (firms): 46/61.

First of all, it should be noted that Harris and Li (2010) experimented with the same trick as Disney and Others (2003) and end up with quite different results. Second, in fact the relationship Disney and Others (2003) should have found was a U-shaped one between the real manufacturing output growth and the hazard of exit, if they had fitted a binomial specification, let's say, a quadratic one. As they may have fitted in econometric terms almost the same variable twice, one fitted the downtrend and the other the uptrend of the quadratic specification. The multiplying of the real manufacturing output growth by age may have not significantly modified the former variable. Table XI exhibits results from an experiment with the reference study data that demonstrate the conjecture is well founded. Auxiliary equation (1) clearly shows that there is a binomial relationship between the manufacturing sector growth rate and the hazard of exit. Auxiliary equation (2) shows results from the misguided attempt to fit a monotonic specification, that is, exactly what Disney and Others (2003) obtained before adding the interaction for their industry growth rate. Auxiliary equation (3) shows that substituting the interaction between the manufacturing sector sales growth rate and year of exit or of censoring, ranging from 1 to 13 , for 
one of the terms of the binomial specification in the auxiliary equation (1) results in a significant monotonic relationship between the interaction and the hazard rate, only with the sign reversed in relation to the other term of the auxiliary equation (1) that was not dropped out from it. The Pearson correlation coefficient shown in the table is high enough to mean that the interaction kept much of the manufacturing sector sales growth rate content. Age in Disney and Others (2003)'s study is the same thing as year of exit or of censoring, because theirs is a sample of genuine new firms, followed from birth up to time of exit or of right censoring. The section on Disney and Others (2003)'s analysis of entry and exit rates reach conclusions that after a deep review may be consistent with the reference study theses. Again, the explanation of the reference study is that, in recessions, that is, GDP and industry growth rates falling, incumbent small firms exit because of both low sales levels and competition by new formal and informal small firms, most of which are being created by unemployed people, being pushed into market after losing their jobs because of the recession. In booms, with GDP and industry growth rates rising, incumbent small firms exit because of both some of them belong to pushed small business owners that now want to go back to salaried jobs and new entrepreneurs pulled into the market by high success prospects.

TABLE XII - EXTERNAL DETERMINANTS OF SMALL BUSINESS SURVIVAL/EVOLUTION ON TIME

\begin{tabular}{|c|c|c|c|c|c|c|c|c|c|c|}
\hline \multirow{4}{*}{$\begin{array}{c}\begin{array}{c}\text { Regressors/Independent } \\
\text { Variables }\end{array} \\
(\text { GDP growth rate }+1)^{(1 / 2)+}\end{array}$} & \multicolumn{10}{|c|}{ COX PROPORTIONAL HAZARD MODEL } \\
\hline & \multicolumn{10}{|c|}{ Auxiliary Equations } \\
\hline & \multicolumn{2}{|c|}{$1 / 5$ of time span } & \multicolumn{2}{|c|}{$2 / 5$ of time span } & \multicolumn{2}{|c|}{$3 / 5$ of time span } & \multicolumn{2}{|c|}{$4 / 5$ of time span } & \multicolumn{2}{|c|}{ Full time span } \\
\hline & -14.99 & $(3.91)^{\star \star \star}$ & -8.52 & $(4.03)^{* * *}$ & -8.48 & $(4.36)^{\star * *}$ & -7.26 & $(4.01)^{\star * *}$ & -9.11 & $(5.29)^{\star * *}$ \\
\hline$(\text { GDP growth rate }+1)^{(1)+}$ & 4.36 & $(3.80)^{\star \star \star}$ & 2.38 & $(3.80)^{\star * *}$ & 2.29 & $(3.95)^{\star \star \star}$ & 1.90 & $(3.52)^{\star \star \star}$ & 2.48 & $(4.92)^{\star \star \star}$ \\
\hline $\begin{array}{c}\text { Manufacturing sector sales } \\
\text { growth rate }\end{array}$ & -0.03 & $(1.74)$ & -0.01 & $(0.85)$ & $0.66 \mathrm{e}-3$ & $(0.08)$ & $-0.20 \mathrm{e}-2$ & $(0.25)$ & $-0.12 \mathrm{e}-2$ & $(0.15)$ \\
\hline $\mathrm{R}_{\mathrm{p}}^{2}$ & \multicolumn{2}{|c|}{0.46} & \multicolumn{2}{|c|}{0.28} & \multicolumn{2}{|c|}{0.34} & \multicolumn{2}{|c|}{0.32} & \multicolumn{2}{|c|}{0.40} \\
\hline LR chi2(3/3/3/3/3) & \multicolumn{2}{|c|}{$38.15^{\star * *}$} & \multicolumn{2}{|c|}{$19.87^{\star \star \star}$} & \multicolumn{2}{|c|}{$25.68^{\star \star *}$} & \multicolumn{2}{|c|}{$23.46^{* * *}$} & \multicolumn{2}{|c|}{$31.61^{* * *}$} \\
\hline Number of events/cases & \multicolumn{2}{|c|}{$16 / 61$} & \multicolumn{2}{|c|}{ 29/61 } & \multicolumn{2}{|c|}{$37 / 61$} & \multicolumn{2}{|c|}{$41 / 61$} & \multicolumn{2}{|c|}{$46 / 61$} \\
\hline
\end{tabular}

Obs: 1) First values in the main body of the table are coefficient estimates; 2) numbers in parentheses are absolute value $\mathrm{z}$-statistics; 3) *,**, and $* * *$ denote statistical significance at the $5 \%, 1 \%$, and $0.1 \%$ levels, respectively; 4) + Adding 1 was necessary in order to make it possible to extract the square root for the originally negative values.

Audretsch and Others (2004) came across with lack of statistical significance for the relationship between the industry growth rate and the hazard rate in the full follow-up span. This would be evidence in favor of the frame of reference, since it predicts this result from a misguided attempt to fit a linear specification when the actual U-shaped relationship is perfectly or almost perfectly symmetrical. However, the authors also found the expected relationship between the industry entry rate and the hazard of exit in the same equation. In this case, there is the new proposed framework prediction that one variable should capture the downtrend whereas the other should capture the uptrend of the actual U-shaped relationship. In this case, Audretsch and Others (2004)'s results are against the predictions of the new proposed framework. On the other hand, the new proposed framework predicts that the industry entry rate is correlated to both the GDP growth rate and the industry growth rate in a U-shaped relationship. In such a case, the industry entry rate is an absolute value version of both the GDP growth rate and the industry growth rate. Thus, Audretsch and Others (2004) are fitting two related variables, with the result that one measure can trouble the other, even though the industry entry rate is computed at the start-up year. As the authors presented results for the same sample for six points in time, it is clearly visible that as time goes forward the fitting for the industry entry rate gets better and better and that for the industry growth rate gets worse and worse, until the industry entry rate becomes highly statistically significant and the industry growth rate loses all its initial statistical significance. Probably the 
industry entry rate is playing the role of the GDP growth rate. Equations (9) to (11) of Panel 3 in Table I shows that in the reference study the impact of the GDP growth is much stronger and that its fitting together with the industry growth rate results in this latter variable losing all its previously high statistical significance. Table XII, in which the GDP growth rate substitutes for the industry entry rate, shows results from the reference study very similar to those reported by Audretsch and Others (2004), except for the sign. The econometric interpretation is that, as time goes by, with the accumulation of events, the fitting for either the industry entry rate, in Audretsch and Others (2004)'s study or the GDP growth rate, in the present one, gets more and more "tuned" to the actual U-shaped relationship so that not many residuals are left to be captured by the additional fitting of the industry growth rate.

Christie and Sjoquist (2012)'s study provides a most interesting case for reviewing, which lends strong support for the findings and predictions of the reference study. Lack of statistical significance of the industry growth rate in Christie and Sjoquist (2012)'s study might be either the predicted result from a misguided attempt to fit a linear specification when the actual U-shaped relationship is perfectly or almost perfectly symmetrical or due to the GDP growth rate taking way the explanatory power from the industry growth rate once these two variables are normally correlated to each other, as it is the case of the reference study. Such an interpretation becomes even more convincing when it is observed that the industry entry rate might be playing in Christie and Sjoquist (2012)'s study the role of the second term of the actual U-shaped relationship between the GDP growth rate and the hazard of exit, once it is, according to interpretations of the reference study, an absolute value version of either the GDP growth rate or the industry growth rate. A last possibility, with the same implication, would be that it is possible that in Christie and Sjoquist (2012)'s equations the GDP growth rate and the unemployment rate, that normally are highly correlated and trouble one another when entering contemporaneously the same regression equation, are playing the roles of the two terms of the "correct" binomial specification that should have been instead fitted for capturing the effects of the GDP growth rate.

Last, there is the Fernandes and Paunov (2015)'s empirical work that specified industry sales growth monotonically and found no association with the hazard of exit in view of total lack of statistical significance. In this case, there are no more subsidies, reported or informed, to take the evidence further than the allegation that it lends support to the findings of the reference study since it is one of its prediction that lack of statistical significance is the result of failure of fitting a binomial specification and of the misguided attempt to fit a linear specification to an actual symmetric U-shaped relationship.

\subsection{INDIRECT EVIDENCE}

Wennekers and Others (2005) and Wennekers and Others (2010) are two works that lend support to the reference study main finding, namely, the U-shaped relationship between the small manufacturing enterprises' hazard of exit and the GDP growth rate. However, their support is not direct, as they presented results from analyses of an investigated U-shaped relationship between stage of economic development, instead of the GDP growth rate, and level of independent entrepreneurship. The interpretation advanced in the reference study for its finding is that the small firms' high likelihood of exit at low GDP growth rates is due to a significant extent to increased competition from new businesses created by necessity entrepreneurs and that the small firms' high likelihood of exit at high GDP growth rates is due to increased competition from new businesses created by opportunity entrepreneurs. Wennekers and Others (2005) and Wennekers and Others (2010)'s conclusions that there exists a U-shaped relationship between the proportion of new-firm start-ups, both necessity and opportunity entrepreneurs, in the economy and the level of income per capita of different countries at varying levels of economic development is not 
exactly the same as the finding from the reference study. Besides, Wennekers and Others (2005) themselves report a table of cross-correlations in which bivariate correlation coefficients between economic growth and per capita income are negative and statistically insignificant. However, there must be consistency between the findings of the reference study and those of these authors, in view of the fact that there does not appear to be another way through which the U-shaped relationship between economic development and the existence of new startups among different countries would build up other than through a U-shaped relationship between GDP growth and entry rate over time and inside each studied country. After all, countries normally do not achieve economic development without achieving GDP growth.

Calá (2014) reported tables of Poisson model panel analyses for the determinants of entry and exits of enterprises in Argentina. The level of informality in the economy measured for the provinces and years of the study correlates with the exit rate of enterprises in a U-shaped relationship at moderate and high levels of statistical significance. The level of poverty measured for the provinces and years of the study correlates with the entry rate of new enterprises in a Ushaped relationship at high levels of statistical significance. The author informed that did not work with the GDP growth official figures since they are misleading for the studied period, both in local currency and in US dollars, because of inflation and severe devaluation of the Argentinean peso.

This is the only one piece of direct empirical evidence at the enterprise level in support of the thesis of the reference study. In the vast empirical literature reviewed no other study presented results for the fitting of a binomial specification and not a single author informed whether had tried the fitting. Calá (2014) did not work with the GDP growth rate, which is central in the reference study, but hopefully the levels of poverty and informality, on the one hand, and the GDP growth rate, on the other hand, are associated to each other. Thus, low GDP growth rates, or even negative rates, would be associated with high informality and poverty levels, which on their turn are associated with high exit rates of incumbent firms and high entry rates of new small businesses, probably initiated by "push" entrepreneurs. Also, high GDP growth rates would be associated with low informality and low poverty levels, which on their turn are associated with high exit rates of incumbent firms and high entry rates of new small businesses, probably initiated by "pull" entrepreneurs. Of course, the exit by incumbent firms, in the case of low GDP growth rates, is not the effect of new competition by "push" entrepreneurs only, but also by the downturn of economic activity itself and by new competition also on the part of free-lance business men. Perhaps, that is why the level of statistical significance of the negative term of the fitted quadratic specification for informality is inferior to that of the second term.

Fotopoulos (2014), in his Ph.D. thesis, presents Figure 3.1, in which the mean net entry rates for 10 years are plotted against the respective GDP growth rates for a sequence of 10 years. Taking the values from this graph, it was possible to build Table XIII, which shows the fitting of three different specifications to capture in the linear regression model the influence of the GDP growth rate on the enterprises' probability of exit. So, equation (1) of Panel 1 confirms the negative monotonic relationship obtained by the authors with the full sample, all covariates and the net entry rates individualized by the enterprises. Equations (2) and (3) show that in fact the actual relationship is U-shaped, confirming the new proposed framework prediction. In Panel 2 of Table XIII the same exercise is carried out for the sub-sample of large firms, whose values were taken from Fotopoulos (2014)'s Figure 5.1. As there is no statistical significant association in this sub-sample, the conclusion is that the results for the whole sample are driven by the small firms' subset, and confirm findings of other studies the larger enterprises are not much affected by macroeconomic and sectorial conditions. However, it should be noted that in the regressions with the full sample, all covariates and the net entry rates individualized by the enterprises Fotopoulos (2014) reports a contradictory statistically significant positive relationship. 
EXTERNAL DETERMINANTS OF SMALL BUSINESS SURVIVAL

TABLE XIII - EXTERNAL DETERMINANTS OF BUSINESS NET ENTRY PANEL 1 ALL SIZES

\begin{tabular}{|c|c|c|c|c|c|c|}
\hline \multirow{3}{*}{$\begin{array}{c}\text { Regressors/Independent } \\
\text { Variables }\end{array}$} & \multicolumn{6}{|c|}{ LINEAR REGRESSION MODEL } \\
\hline & \multicolumn{6}{|c|}{ Auxiliary Equations } \\
\hline & \multicolumn{2}{|c|}{ (1) } & \multicolumn{2}{|c|}{ (2) } & \multicolumn{2}{|c|}{ (3) } \\
\hline$($ GDP growth rate+1)(1)(1)(1/2) + & -0.54 & $(2.10)$ & -2.80 & $(3.18)^{*}$ & -11.50 & $(4.46)^{\star \star}$ \\
\hline$($ GDP growth rate+1)(na) (2) (1) + & n.a. & n.a. & 0.39 & $(2.63)^{*}$ & 3.21 & $(3.77)^{\star *}$ \\
\hline Constant & 1.33 & $(1.52)$ & 3.43 & $(3.31)^{*}$ & 8.87 & $(5.05)^{\star *}$ \\
\hline $\mathrm{R}^{2}$ adjusted & \multicolumn{2}{|c|}{0.27} & \multicolumn{2}{|c|}{0.58} & \multicolumn{2}{|c|}{0.78} \\
\hline$F(1,8 / 2,7 / 2,7)$ & \multicolumn{2}{|c|}{4.39} & \multicolumn{2}{|c|}{$7.28^{*}$} & \multicolumn{2}{|c|}{$17.36^{\star *}$} \\
\hline
\end{tabular}

PANEL 2100 EMPLOYEES OR MORE

\begin{tabular}{|c|c|c|c|c|c|c|}
\hline \multirow{3}{*}{$\begin{array}{l}\text { Regressors/Independent } \\
\text { Variables }\end{array}$} & \multicolumn{6}{|c|}{ LINEAR REGRESSION MODEL } \\
\hline & \multicolumn{6}{|c|}{ Auxiliary Equations } \\
\hline & \multicolumn{2}{|c|}{ (1) } & \multicolumn{2}{|c|}{$(2)$} & \multicolumn{2}{|c|}{$(3)$} \\
\hline$($ GDP growth rate+1)(1)(1)(1/2) + & $-0.53 E-2$ & $(0.01)$ & -4.64 & $(1.80)$ & -14.57 & (1.31) \\
\hline$($ GDP growth rate+1)(na) (2) (1) + & n.a. & n.a. & 0.80 & $(1.84)$ & 4.75 & (1.30) \\
\hline Constant & -2.11 & $(1.03)$ & 1.94 & $(0.69)$ & 7.28 & $(0.98)$ \\
\hline $\mathrm{R}^{2}$ adjusted & \multicolumn{2}{|c|}{0.00} & \multicolumn{2}{|c|}{0.15} & \multicolumn{2}{|c|}{0.00} \\
\hline $\mathrm{F}(1,7 / 2,6 / 2,6)$ & \multicolumn{2}{|c|}{0.00} & \multicolumn{2}{|c|}{1.69} & \multicolumn{2}{|c|}{0.86} \\
\hline
\end{tabular}

Obs: 1) First values in the main body of the table are coefficient estimates; 2) numbers in parentheses are absolute value $\mathrm{t}$-statistics; 3 ) $* * *$, and $* * *$ denote statistical significance at the $5 \%, 1 \%$, and $0.1 \%$ levels, respectively; 4) + Adding 1 was necessary in order to make it possible to extract the square root for the originally negative values; 5) Number of observations: $10 / 9$.

\section{CONCLUSIONS, STRENGHTS AND LIMITATIONS OF THE STUDY AND SUGGESTIONS FOR FUTURE RESEARCH AND SMALL BUSINESS DEVELOPMENT SUPPORT POLICIES}

The present study has successfully demonstrated that its posited framework of reference for research dealing with the relationships between, on the one side, the GDP growth rate and the industry growth rate and, on the other side, small business survival is highly invaluable in face of strong support lent by three robust sources. Firstly, by an in-depth piece of research that investigated a very wide range of postulated determinants of small business survival. Secondly, by the power of the postulated framework of reference to explain a set of unexpected, embarrassing and unacceptable findings in the extant literature on small business survival. Out of numerous reviewed studies, some unexpected results from only two works were not explained by the new proposed framework, but, on the other hand, flaws and contradictions were found in their sampling strategy and variable building. Thirdly, by studies in related fields that indirectly lend support to the findings of the reference study.

The achievements of the present study are surprisingly numberless and diversified. First statistical significance is generally very high. The GDP growth rate and the industry growth rate are confirmed as major determinants of the small manufacturing enterprises' hazard of exit. This is robust in specifications either by themselves or together with other sectorial and macroeconomic variables. Only that the relationships are U-shaped, being this piece of finding by far the greatest breakthrough brought about by the study. When fitted contemporaneously with the variables 


\section{EVALDO GUIMARÃES BARBOSA}

investigated in the original, reference study, the GDP growth rate behaves in a way consistent with the interpretation that the state of the macroeconomic environment strongly determines that small enterprises will exit, but what determines which ones is the strategies set at the level of the small enterprises and the risks they individually face. Also, consistent with the common sense, the enterprises that have more debt and that are facing higher risks, and, against theory, that should be shielded, because are operating in niche markets, are the most affected by macroeconomic conditions. Moreover, confrontation of the GDP growth rate with size and age of the firm produces results that are consistent with the interpretation that the smaller and the younger small manufacturing enterprises are the most impacted by macroeconomic conditions. The robust findings allowed the postulation of a new framework that best represents the relationship between the GDP growth rate and small business survival, which is proposed for investigating, analyzing and interpreting such a relationship, being it either central to the study or included only as a control. Also, many predictions from the findings or from interpretations of the findings were also developed. Finally, this framework and its predictions were used to confront results in the extant literature in search for extra support for the findings and theses of the present study. This effort was successful in view of the fact that the greatest portion of the literature adjusted itself to the new proposed framework.

Of course, it has to be acknowledged that the main limitation of this work is that it is partly based upon a piece of research that dealt with a very small sample. This, in fact, has been duly done to the extent that recourse was taken to the extant related literature to search for external support to its findings and postulations. In general, other research efforts are characterized by the use of samples of huge sizes. On the other hand, it has strengths, represented by the use of large number of covariates defined at the enterprise level, non-linear specifications and combinations of exponents for the binomial specifications other than the quadratic combination. However, the greatest strength of the research is that its methodology resulted in numerous important findings.

So, it is imperative to state that empirical research interested in understanding the same or phenomena related to the ones investigated in this study should pursue more vigorously the use of an ampler array of covariates, mainly the ones defined at the level of the enterprise, the fitting of non-linear specifications, and the choice of binomial power combinations other than the quadratic one. Other suggestions for future research in the area have to do with the predictions made and tested in this study. Thus, one is that researchers should take care concerning overfitting. Before specifying independent variables to enter regressions, a lot of work should be done to check whether or not they are associated to each other, not least because they may be related nonlinearly. If their relationships with the dependent variable are strong equally, both variables may come out from the analyses as statistically insignificant.

Some suggestions for future research come from the revision work mainly because of technical difficulties faced in carrying out such a task. A first suggestion is that all studies dealing with either new small firms or incumbent ones, or even a mix of them, should present separate results for micro-, small-, medium- and large-sized enterprises. It is becoming clear that each of these categories of size have its own set of survivorship determinants, which in turn have individually a particular way of working, there existing cases that the determinants behave differently depending on which category of size is under consideration. Treating all categories of size alike hinders the development of meaningful theories of small business survivorship. A second suggestion is that authors should report more fully summary statistics and correlations between the variables of their studies. This eases understanding and evaluation of their results. 
The value of this orientation is highlighted when it is recalled that science is an endless process of accumulation of knowledge carried out bit by bit through the contribution of new researchers that add on the achievements of previous ones.

As to theory building, it will be no surprise if insights from this piece of research bring in new and promising lines of investigation in the field of industry dynamics and the workings of the economy. For, many issues spontaneously sprout from the realization that the basic relationships between, on the one hand, the small firms' hazard of exit, and, on the other hand, the GDP growth rate and the industry growth rate are U-shaped. Also, from the realization that there are more births and deaths for this segment of enterprises during both cyclical downturns and upturns in the economy, coming higher competition in the economy in the first case from necessity entrepreneurs and in the second case from opportunity ones. And, also yet, from the realization that the larger enterprises are not so much affected in terms of survival probability from such swings in the economy. Thus, a pertinent question is whether such "facts" mean that what happens is in most cases a global readjustment of internal production in response to either an imported recession or boom to a new equilibrium in the whole economy. Another one is whether there are distinct roles to played in this global adjustment for the small and the large companies, such as the small firms are the buffer and the large firms the shielded ones. If all this is so, another pertinent issue concerns the so much propagated cleasing effects of recessions, whether much room is left for them. Another pertinent and interesting question is whether these conclusions are the ones that Birch (1977) should have reached back their when he was writing his Ph.D. thesis, 40 years ago, when was in the brink of causing all the world renowed interest in small firms. That is, the small firms were not only creating new jobs while their larger counterparts were pouring jobs, but were also readjusting, or at least, helping to readjust the economy as a whole.

These points may not seem to be so strange conjectures when associated with the conclusions reached by Wennekers and Others (2005), who gathered much evidence of the existence of a U-shaped relationship between stage of economic development and level of independent entrepreneurship. They say that their results suggest that a "natural rate" of entrepreneurship is to some extent governed by "laws" related to the level of economic development and that related studies finds that the impact of entrepreneurial dynamics on economic growth is considerably smaller (or even negative) for developing countries than for more highly developed economies. If the role of entrepreneurship in developing countries is not promote economic growth, it might be preserving it by adjusting, or at least, helping to adjust it to a new equilibrium in the event of macroeconomic swings.

Wennekers and Others (2005) concluded that low-income nations, given their stage of development, should not consider the promotion of new business start-ups as a top priority on their policy agenda, but that, instead, they should invest in the management qualities of their population and foster the exploitation of scale economies through the growth of young businesses. This orientation is espoused here, if only because suggestion given in the study that served as a reference to this one, which investigated the determinants of small business survival at the company level, was that governmental support to the development of small businesses should focus on the provision of financial and managerial assistance. Now, more so, because it became clear in the present study that management competency most probably is accountable for the higher resilience of large enterprises to recessions. Last, but not least, care should be taken that technological and administrative modernization do not cause so a radical change in the nature of 
the assisted small enterprises that they end up suffering from the shortcomings of bigness without getting rid of those of smallness.

\section{REFERENCES}

Anagnostaki, V. and H. Louri (1995), Entry and exit from Greek manufacturing industry: a test of the symmetry hypothesis, International Review of Applied Economics 9(1): 86-95.

Audretsch, David B. (1995), Innovation, growth and survival, International Journal of Industrial Organization - Special issue: the Post Entry Performance of Firms 13(4):441-57.

Audretsch, David B., Patrick Houweling and A. Roy Thurik (2004), Industry Evolution: Diversity, Selection and the Role of Learning, International Small Business Journal 22(4): 331-48.

Audretsch, David B. and Talat Mahmood (1995), New Firm Survival: New Results Using a Hazard Function, Review of Economics and Statistics 97:97-103.

Barbosa, Evaldo Guimarães (2009), Common Determinants of the Firm's Capital Structure and Business Survival - The Case of Very Small Enterprises of Traditional Manufacturing Sectors in Brazil, Charleston, SC, USA.

Barbosa, Evaldo Guimarães (2016), Determinants of Small Business Survival: The Case of Very Small Enterprises of the Traditional Manufacturing Sectors in Brazil, Working Paper.

Barbosa, Evaldo Guimarães (2016b), The Relationships Between, on the one hand, Size, Growth and Age of the Firm and, on the other hand, Small Business Survival - A Constructive Critique and a Proposal of a New Framework, Working Paper.

Bertin, Amy L., Timothy F. Bresnahan and Daniel M. G. Raff (1996), Localized Competition and the Aggregation of Plant-Level Increasing Returns: Blast Furnaces, 1929-1935, Journal of Political Economy 104(2): 241-66.

Boeri, Tito and Lutz Bellmann (1995), Post-entry behaviour and the cycle: Evidence from Germany, International Journal of Industrial Organization 13: 483-500.

Buehler, Stefan, Christian Kaiser and Franz Jaeger (2006), Merge or Fail? The Determinants of Mergers and Bankruptcies in Switzerland, 1995-2000, Economics Letters 90(1):88-95.

Buehler, Stefan, Christian Kaiser and, Franz Jaeger (2012), The geographic determinants of bankruptcy: evidence from Switzerland, Small Business Economics 39:231-251.

Bunn, Philip and Victoria Redwood (2003), Company accounts based modelling of business failures and the implications for financial stability, Working Paper no. 210, Bank of England.

Calá, Carla Daniela (2014), Regional Issues on Firm Entry and Exit in Argentina: Core and Peripheral Regions, PhD Dissertation, Department of Economics, Universitat Rovira i Virgili, Reus, Argentina.

Calá, Carla Daniela (2015), Firm Dynamics in Developing Countries: A Single Policy for all Regions?, Working paper, Facultad de Ciencias Económicas y Sociales (Universidad Nacional de Mar del Plata) Funes - Mar del Plata (Argentina).

Carreira, Carlos and Paulino Teixeira (2011), The shadow of death: analysing the pre-exit productivity of Portuguese manufacturing firms, Small Business Economics 36:337-51.

Christie, Tamoya and David L. Sjoquist (2012), New Business Survival in Georgia: Exploring the Determinants of Survival Using Regional Level Data, Growth and Change 43(1):110-42.

Disney, Richard, Jonathan Haskel and Ylva Heden (2003), Entry, Exit and Establishment Survival in UK Manufacturing, The Journal of Industrial Economics 51, Issue 1 (March): 91-112. 
Everett, Jim and John Watson (1998), Small Business Failure and External Risk Factors, Small Busines Economics 11(4):371-90.

Falk, Martin (2012), A survival analysis of ski lift companies, Tourism Management xxx: 1-14.

Farinha, Luisa A. (2005), The Survival of New Firms: Impact of Idiosyncratic and Environmental Factors, Financial Stability Report 2005, Banco de Portugal.

Feizpour, Mohammad Ali, Hossain Hajikhodazadeh and Abolfazl Shahmohammadi Mehrjardi (2014), Life Duration of New Firms in Iranian Manufacturing Industries Using Cox Proportional Hazard Model, Iranian Economic Review 18(3):133-56.

Fernandes, Ana M. and Caroline Paunov (2015), The Risks of Innovation: Are Innovating Firms Less Likely to Die?, The Review of Economics and Statistics 97(3):638-53. July.

Fotopoulos, Giorgios and Helen Louri (2000a), Determinants of Hazard Confronting New Entry: Does Financial Structure Matter?, Review of Industrial Organization 17:285-300.

Andraz, Georgette, J. Sant'ana Fernandes, Cristina Gonçalves and J. Rodrigo Guerreiro (2015), Portuguese manufacturing industry: determinants of new firm entry, Tourism \& Management Studies 11(2): 138-45.

Georgios Fotopoulos (2014), The Determinants of Firm Entry and Exit into Greek Manufacturing Industries: Sectoral, Temporal and Spatial Variation, Ph.D. Thesis, The London School of Economics and Political Science, University of London.

Geroski, Paul A. (1995), What do we know about entry?, International Journal of Industrial Organization - Special issue: the Post Entry Performance of Firms 13:421-40.

Geroski, Paul A., José Mata and Pedro Portugal (2010), Founding Conditions and The Survival of New Firms, Strategic Management Journal 31(5):510-29.

Gimeno, J., T. Folta, A. Cooper, C. Woo (1997), Survival of the fittest? Entrepreneurial human capital and the persistence of underperforming firms, Administrative Science Quarterly 42: 750-83.

Harris, R. and Q.C. Li (2010), Export-market dynamics and the probability of firm closure: evidence for the United Kingdom, Scottish Journal of Political Economy 57(2):145-68.

Helmers, Christian and Mark Rogers (2010), Innovation and the Survival of New Firms in the UK, Review of Industrial Organization 36(3): 227-48.

Holmes, Phil, Paul Braidford and Ian Stone (2010), An analysis of new firm survival using a hazard function, Applied Economics 42(2).

Hosmer, David W. Jr. and Stanley Lemeshow (1999), Applied Survival Analysis - Regression Modeling of Time to Event Data, John Wiley \& Sons, New York, NY.

Ilmakunnas, Pekka and Jukka Topi (1999), Microeconomic and Macroeconomic Influences on Entry and Exit of Firms, Review of Industrial Organization 15: 283-301.

Jensen, Paul H., Elizabeth Webster and Hielke Buddelmeyer (2008), Innovation, technological conditions and new firm survival, The Economic Record 84:434-48.

Klapper, Leora and Christine Richmond (2011), Patterns of business creation, survival and growth: Evidence from Africa, Labour Economics 18: S32-S44.

Low, Murray B. and Ian C. MacMillan (1988), Entrepreneurship: Past Research and Future Challenges, Journal of Management 14(2):139-61.

Mahmood, Talat (1992), Does the Hazard Rate of New Plants Vary between High-and-Low-Tech Industries?, Small Business Economics 4(3):201-210.

Mata, José, Pedro Portugal and Paulo Guimarães (1995), The survival of new plants: Start-up conditions and post-entry evolution, International Journal of Industrial Organization 13:45981. 


\section{EVALDO GUIMARÃES BARBOSA}

Oh, Inha, Almas Heshmati, Chulwoo Baek and Jeong-Dong Lee (2009), Comparative Analysis of Plant Dynamics by Size: Korean Manufacturing, The Japanese Economic Review 60(4): 512-38. December.

Resende, Marcelo, Vicente Cardoso and Luis Otávio Façanha (2016), Determinants of survival of newly created SMEs in the Brazilian manufacturing industry: an econometric study, Empirical Economics 50(4):1255-74.

Shiferaw, Admasu (2009), Survival of private sector manufacturing establishments in Africa: The role of productivity and ownership, World Development, Elsevier 37(3):572-84.

Stonebraker, Robert J. (1979), Turnover and Mobility among the 100 Largest Firms: An Update, The American Economic Review 69(5): 968-73.

Strotmann, Harald (2007), Entrepreneurial Survival, Small Business Economics 28:87-104.

Varum, Celeste, Vera Catarina Rocha and Hélder Valente da Silva (2014), Economic slowdowns, hazard rates and foreign ownership, International Business Review 23:761-73.

Wennekers, Sander, André van Stel, Roy Thurik and Paul Reynolds (2005), Nascent Entrepreneurship and the Level of Economic Development, Small Business Economics 24:293-309.

Wennekers, Sander, André van Stel, Martin Carree and Roy Thurik (2010), The Relationship between Entrepreneurship and Economic Development: Is It U-Shaped?, Foundations and Trends in Entrepreneurship 6(3): 167-237.

\section{APPENDICES:}

Appendix I Survival Variables Summary Statistics

\begin{tabular}{c|c|c|c|c}
\hline Variables & Mean & $\begin{array}{c}\text { Standard } \\
\text { Deviation }\end{array}$ & Minimum & Maximum \\
\hline Duration (1) & $2,455.62$ & $1,749.86$ & 21.00 & $4,748.00$ \\
\hline Exit(2) & 0.75 & 0.43 & 0.00 & 1.00 \\
\hline GDP growth rate (22) & 2.91 & 2.02 & -0.50 & 5.90 \\
\hline 3-year-lagged GDP growth rate(23) & 2.24 & 2.75 & -4.30 & 5.90 \\
\hline Manufacturing sector sales growth rate (24) & 8.56 & 21.38 & -29.97 & 50.26 \\
\hline Manufacturing sector performance (25) & -6.87 & 10.00 & -25.46 & 10.48 \\
\hline 1998 year dummy (26) & 0.11 & 0.32 & 0.00 & 1.00 \\
\hline Unemployment rate (27) & 9.87 & 1.17 & 8.30 & 12.30 \\
\hline
\end{tabular}

\begin{tabular}{c|c|c|c|c|c}
\hline \multirow{2}{*}{ Variables } & \multicolumn{3}{|c|}{ Fractiles } & \multirow{2}{*}{ Kurtosis $^{*}$} & \multirow{2}{*}{ Skewness } \\
\cline { 2 - 6 } & 0.10 & 0.50 & 0.90 & \\
\hline Duration (1) & 82.40 & $1,980.00$ & $4,748.00$ & -1.55 & 0.16 \\
\hline Exit(2) & 0.00 & 1.00 & 1.00 & -0.56 & -1.21 \\
\hline GDP growth rate (22) & -0.50 & 3.20 & 5.70 & -0.81 & -0.44 \\
\hline 3-year-lagged GDP growth rate(23) & -3.54 & 2.70 & 5.90 & 0.97 & -1.09 \\
\hline Manufacturing sector sales growth rate (24) & -12.86 & 8.08 & 47.49 & -0.07 & 0.38 \\
\hline Manufacturing sector performance (25) & -21.19 & -9.44 & 5.26 & -0.94 & -0.09 \\
\hline 1998 year dummy (26) & 0.00 & 0.00 & 1.00 & 4.28 & 2.48 \\
\hline Unemployment rate (27) & 8.30 & 9.80 & 11.50 & -0.68 & 0.30 \\
\hline
\end{tabular}

Obs.: 1) Number of cases: $61 ; 2$ ) *According to Norušis (1992, p.167), in the SPSS the value of kurtosis for the normal distribution is, differently from many textbooks in statistics, 0 and not 3 . 
EXTERNAL DETERMINANTS OF SMALL BUSINESS SURVIVAL

Appendix II Survival Variables Intercorrelation Matrix

\begin{tabular}{|c|c|c|c|c|c|c|}
\hline & $\begin{array}{l}\text { GDP } \\
\text { growth } \\
\text { rate } \\
(22)\end{array}$ & $\begin{array}{c}\text { 3-year- } \\
\text { lagged GDP } \\
\text { growth rate } \\
(23)\end{array}$ & $\begin{array}{c}\text { Manufacturin } \\
\text { g sector sales } \\
\text { growth rate } \\
\text { (24) }\end{array}$ & $\begin{array}{l}\text { Manufacturi } \\
\text { ng sector } \\
\text { performanc } \\
\text { e (25) }\end{array}$ & $\begin{array}{c}1998 \\
\text { year } \\
\text { dummy } \\
(26)\end{array}$ & $\begin{array}{c}\text { Unemploy } \\
\text { ment rate } \\
(27)\end{array}$ \\
\hline Duration (1) & 0.29 & 0.15 & \begin{tabular}{|l|}
0.04 \\
\end{tabular} & 0.65 & -0.13 & 0.47 \\
\hline Exit(2) & -0.08 & -0.10 & 0.03 & -0.35 & 0.21 & 0.04 \\
\hline Net working capital (3) & 0.20 & -0.18 & 0.06 & 0.16 & -0.17 & 0.15 \\
\hline Total financial leverage (4) & 0.07 & 0.18 & 0.19 & 0.02 & 0.31 & 0.09 \\
\hline $\begin{array}{c}\text { Medium- and long-term financial } \\
\text { leverage(5) }\end{array}$ & -0.12 & -0.00 & -0.20 & -0.22 & -0.02 & -0.11 \\
\hline Profitability (6) & 0.13 & 0.01 & 0.03 & 0.28 & 0.25 & 0.12 \\
\hline Operational cycle (7) & -0.00 & 0.06 & 0.08 & 0.01 & 0.02 & 0.07 \\
\hline Machinery/fixed assets ratio (8) & -0.08 & -0.25 & 0.17 & -0.13 & -0.20 & -0.04 \\
\hline Automation degree (9) & 0.06 & -0.06 & 0.07 & -0.04 & 0.10 & 0.01 \\
\hline Corporate diversification (10) & 0.13 & -0.06 & 0.15 & 0.09 & 0.10 & 0.15 \\
\hline Market concentration (11) & 0.13 & -0.10 & -0.28 & 0.08 & 0.00 & -0.19 \\
\hline Client concentration (12) & 0.10 & -0.17 & -0.02 & 0.14 & -0.34 & -0.06 \\
\hline Sales concentration in big clients (13) & 0.02 & 0.02 & 0.16 & -0.22 & -0.07 & -0.08 \\
\hline Sales unpredictability (14) & -0.27 & 0.04 & -0.27 & -0.20 & -0.01 & -0.17 \\
\hline Entrepreneur's risk tolerance (15) & -0.08 & -0.02 & 0.11 & -0.20 & 0.14 & -0.07 \\
\hline Total assets (16) & 0.11 & 0.01 & 0.16 & 0.02 & 0.22 & 0.20 \\
\hline Sales (17) & 0.26 & -0.00 & 0.25 & 0.09 & 0.25 & 0.26 \\
\hline Number of employees (18) & 0.17 & -0.04 & 0.18 & 0.11 & 0.04 & 0.22 \\
\hline Firm age (19) & -0.10 & 0.20 & -0.15 & -0.06 & 0.01 & 0.04 \\
\hline Growth (20) & -0.01 & 0.06 & 0.12 & 0.14 & 0.08 & -0.02 \\
\hline Sales variability (21) & -0.05 & -0.04 & 0.03 & -0.14 & -0.21 & -0.26 \\
\hline GDP growth rate (22) & - & -0.47 & 0.12 & 0.20 & 0.09 & -0.03 \\
\hline 3-year-lagged GDP growth rate (23) & -0.47 & - & 0.08 & 0.25 & 0.48 & 0.42 \\
\hline $\begin{array}{l}\text { Manufacturing sector sales growth } \\
\text { rate (24) }\end{array}$ & 0.12 & 0.08 & - & 0.17 & 0.16 & 0.22 \\
\hline $\begin{array}{c}\text { Manufacturing sector performance } \\
(25)\end{array}$ & 0.20 & 0.25 & 0.17 & - & 0.25 & 0.61 \\
\hline 1998 year dummy $(26)$ & 0.09 & 0.48 & 0.16 & 0.25 & - & 0.30 \\
\hline Unemployment rate (27) & -0.03 & 0.42 & 0.22 & 0.61 & 0.30 & - \\
\hline
\end{tabular}

Obs.: 1) Number of cases: 61 ; 2) Coefficients in absolute values higher than 0.20 are statistically significant at the $5 \%$ level, higher than 0.30 at the $1 \%$, and higher than 0.40 at the $0.1 \%$, in one-tail test. 